[Aus dem hygienischen Institut der Universität Giessen.]

(Director: Geh. Med.-Rath Prof. Dr. Gaffky.)

\title{
Beiträge zur Lehre von der natürlichen Immunität.
}

I. Die cutane Infection.

Von

Dr. Karl Kisskalt,

I. Assistenten des Institutes.

(Hierzu TaP. I-IIr.)

Die Frage nach der Ursache der Pathogenität mancher Bakterien und der natürlichen Immunität mancher Thierarten kann als gelöst betrachtet werden, soweit sie die natürliche Giftimmunität betrifft. Dagegen ist es für die Bakterien, bei denen keine intensire Giftbildung nachweisbar ist, noch nicht bekannt, warum manche von ihnen überhaupt pathogen sind und warum nur für einige Thierarten. Da vielen Bakterien in hohem Maasse die Eigenschaft zukommt, auf allen möglichen Nährböden zu wachsen, so sollte man auch eine solche Wachsthumsfähigkeit im thierischen Körper annehmen; und ein schrankenloses Wuchern von Bakterien muss eine tödtliche Krankheit hervorrufen. Die Frage ist also eigentlich nicht, warum manche Bakterien Krankheit erregen, sondern, warum viele Bakterien. nicht im Stande sind, Krankheit zu erregen.

Zur Lösung dieser Frage wurde meist das Verhalten der Bakterien und des Organismus an der Infectionsstelle kurz nach Einbringung untersucht, da man annahm, dass sich dort ihr Schicksal entscheiden müsse. - Zu der im Folgenden angeführten Litteratur über diesen Gegenstand sei bemerkt, dass die Litteratur über die Infection von Fröschen weggelassen wurde. Einerseits wissen wir nicht, wie weit wir die an diesen gewonnenen Resultate auf die Verhältnisse beim Warmblüter übertragen 
dürfen, da den verschiedenen Thierclassen wenigstens einigermaassen rerschiedene Schutzkräfte zur Verfügung stehen könnten; andererseits finden die Bakterien dort schon wegen der niedrigeren Temperatur ungünstige Verhältnisse vor. An Kaltblütern die Immunität der Säugethiere zu studiren heisst also, in den ohnediess verwickelten Gegenstand noch eine neue Komplikation hereinbringen.

Metschnikoff (33) fand in den ersten Versuchen, die er an Warmblütern anstellte, dass bei Thieren, die für Milzbrand empfänglich waren, die Aufnahme der Milzbrandbacillen in die Leukocyten ausblieb. Führte er dagegen mit abgeschwächtem Milzbrand gefüllte Glascapillaren unter die Haut und zerbrach sie dort, so zeigte sich nach wenigen Stunden reichliche Phagocytose. Die aufgenommenen Bakterien waren dabei stark degenerirt.

Hess (21) füllte Ziegler'sche Kammern (zwei an drei Seiten aneinandergekittete Deckgläschen) mit Milzbrandbacillen und brachte sie empfänglichen und unempfänglichen Thieren subcutan bei. Er fand beim Kaninchen nach 6 bis 8 Stunden mässig viele Leukocyten darin; die Bacillen waren zu Fäden ausgewachsen, die sich zwischen den Leukocyten hindurchschlangen. Nur selten werden intracellulär liegende gefunden. Beim Hund befinden sich fünf bis sechs Mal soviel Leulocyten in der Kammer als beim Kaninchen; es zeigte sich lebhafte Phagocytose, so dass an leukocytenreichen Partieen keine oder fast keine Bacillen frei lagen. Zur Hälfte aufgenommene waren da, wo sie intracellulär lagen, bedentend dünner als an dem extracellulären Ende. Wurde gleichzeitig Jodoform in die Kammer eingebracht, so waren nach derselben Zeit beim Hunde die Bacillen mächtig gewachsen und nur wenige Leukocyten vorhanden. Dasselbe Verhalten wie beim Hunde zeigte sich bei einem natürlich immunen Kaninchen.

van Ermengem (18) kam unabhängig von Hess mit derselben Untersuchungsmethode zu den gleichen Resultaten.

Hess impfte in einer weiteren Arbeit (22) Staphylokokken auf die Hornhaut des Kaninchens. Er constatirte, dass sich die eingeimpften Kokken Anfangs rapid vermehrten; nach kurzer Zeit begann die Phagoeytose und mit fortschreitender Heilung nahm die Zahl der intracellulär gelegenen Kokken immer mehr zu.

Ebenso impfte Wolffheim (65) Staphylokokken auf die Hornhaut von Kaninchen; er fand nach 4 Stunden deutliche, aber nicht sehr starke Wucherung der eingebrachten Kokken; nach 10 Stunden war ihre Zahl bedeutend grösser. Nach 24 Stunden war der ganze Herd von einem Leukocytenwall umgeben über den zahlreiche Kokken hinausgedrungen . 
waren. Phagocytose wurde nicht häufig beobachtet; wo sie vorhanden war, stand sie in keinem Verhältniss zu dem Verlauf der Krankheit.

v. Christmas-Dirkinck-Holmfeldt (13) inficirte Ratten, Mäuse und Kaninchen subcutan mit Milzbrand und untersuchte nach 24 und 48 Stunden, indem er die Wunde öffnete, das Wundsecret aufsaugte und zu Ausstrichpräparaten verwendete. Bei Kaninchen und Mäusen fand er zahlreiche Milzbrandbacillen und keine oder fast keine Eiterkörperchen; bei jungen Ratten, die noch ziemlich empfänglich sind, zahlreiche Bacillen inmitten 'einer grossen Menge Eiterkörperchen; bei alten Ratten eine dicke, gelbe, zähe Eitermasse. Bei hochvirulenten Milzbrandbacillen war diese Eiterbildung weniger ausgesprochen. Impfung mit abgeschwächtem Milzbrand rief bei Kaninchen eine kleine, von Eiterbildung begleitete locale Entzündung hervor; die Thiere blieben am Leben. Phagocytose konnte in sämmtlichen Versuchen nur selten constatirt werden.

Frank (19) führte weissen Ratten, die er für immun gegen Milzbrand hält, Seidenfäden mit Milzbrandbacillen subcutan ein und untersuchte nach 8, 16, 24 Stunden und 2, 3, 5, 6 und 7 Tagen die Infectionsstelle in Schnitten. Er fand, dass die Milzbrandsporen an der Infectionsstelle auskeimen und in dem entstehenden Oedem nach allen Seiten hinauswachsen. Nach 16 Stunden sind zahlreiche Leukocyten zu sehen. Nach 24 Stunden hat der Process der Vermehrung seinen Höhepunkt erreicht; nach 48 Stunden sieht man die Bacillen nicht mehr in das Gewebe hinein, sondern im Gegentheil die dort liegenden wieder nach der Infectionsstelle zurückwachsen. Unterdessen sind in dem den Infectionsherd umgebenden Gewebe, von diesem durch eine Zone getrennt, reichliche Leukocyten zu sehen. Die zwischen diesen liegenden Bacillen gehen zuerst zu Gründe, die anderen etwas später, sämmtliche extracellulär; Frank glaubt, dass durch den Leukocytenmantel die Stoffwechselproducte der Bacillen zurückgehalten und dadurch die Bacillen getödtet würden.

Bumm (12) injicirte Kaninchen Staphylokokkenculturen subcutan. Er fand nach 48 Stunden vier Zonen an der Infectionsstelle: Ein Centrum, wo die Kokken zuerst lagen; eine Wucherungszone der Kokken; eine Coagulationszone; eine Infiltrationszone, die einen Wall von Leukocyten aufbaute und Leukocyten in das verflüssigte Centrum hineinsendete.

Hohnfeldt (23) injicirte ebenfalls Kaninchen Staphylokokken subcutan. Er fand in Schnittpräparaten die Kokken nach 4 Stunden theils frei, theils in Leukocyten; nach 10 Stunden war die Zahl der Kokken wie die der Leukocyten gewachsen, die letzteren überwogen jetzt an Zahl. 
Nach 48 Stunden zeigte sich ein deutlich abgegrenzter Eiterherd: mitten in den Leukocytenhaufen sieht man die Haufen ron Kokken, die nach der Peripherie hin immer spärlicher liegen. Vielfach liegen sie in den Zellen, sind aber auch dann stets gut gefärbt. Vier Tage alte Herde zeigen dieselben Verhältnisse in noch viel ausgesprochenerem Maasse; die Leukocyten gehen zu Grunde, während die Kokken am Leben bleiben. Nach 10 Tagen ist der Abscess in Rückbildung begriffen; seine Kapsel hebt sich scharf gegen das umliegende Gewebe ab. Im Granulationsgewebe finden sich keine Kokken; im Eiter sind dieselben nicht durch Phagocytose zu Grunde gegangen: - Die Eiterkörperchen stammen nicht von den Gewebszellen ab, sondern sind ausnahmslos ausgewanderte Leukocyten.

Czaplewski (14) untersuchte hauptsächlich Tauben, denen er Milzbrandbacillen injicirt hatte. Bei den immunen Tauben gingen die injicirten Bacillen schon nach 4 Stunden zu Grunde; nirgends traten sie, wie Schnittpräparate ergaben, bei ihrem Zerfall mit den Zellen in irgend eine Beziehung. Bei den empfänglichen Thieren war nach dem Tode lebhafte Wucherung der Bacillen an der Infectionsstelle zu sehen, begleitet von reichlichen Wanderzellen.

Bei späteren Versuchen (15), die in derselben Weise angestellt waren, fand er Phagocytose viel häufiger; doch waren auch extracellulär sehr zahlreiche Degenerationsformen zu sehen.

Bitter (8) injicirte Hammeln das Vaccin I des Milzbrandes. Bei dem nach 10 Stunden getödteten Thiere waren weder mikroskopisch noch culturell Bacillen an der Infectionsstelle nachzuweisen; bei dem nach 20 Stunden getödteten waren aus der Infectionsstelle zahlreiche Mikroorganismen zu züchten. Im Schnitt zeigten sich ziemlich reichliche polynucleäre Leukocyten; zwischen diesen lagen sehr viele Milzbrandbacillen, oft in Form langer Fäden. Die Bacillen waren zum grössten Theil bedeutend degenerirt. Bei dem nach 2 Tagen getödteten Hammel fand sich die Infectionsstelle in $1 \mathrm{~cm}$ Umkreis frei von Leukocyten; dann nahm ihre Zahl zu bis $3^{\mathrm{cm}}$ von der Infectionsstelle, dann ab bis $5^{\mathrm{cm}}$. Bacillen fanden sich am meisten in einer Entfernung von $2 \frac{1}{2} \mathrm{~cm}$, meist lange, normal aussehende Fä̉en zwischen den Leukocyten; in $4 \mathrm{~cm}$ Entfernung dagegen keine mehr. Bei dem nach 5 Tagen getödteten Hammel war der Befund, was die Leukocyten betrifft, ungefähr derselbe, nur am Rand waren mehr mononucleäre zu sehen; Bacillen waren nicht mehr nachweisbar. Dass Metschnik off bei Impfung mit dem I. Vaccin reichlich Phagocytose fand, erklärt Bitter damit, dass er kurz nach der Impfung untersuchte und auf diese Weise nur die eingebrachten zu Gesicht bekam, dagegen nicht die, die neu ausgewachsen waren. 
Nuttall (39) brachte wie Metschnikoff mit Milzbrandbacillen gefüllte Glasröhrchen Kaninchen unter die Haut des Ohres. Die Untersuchung geschah an Ausstrichpräparaten. In der ersten Versuchsreihe wurden abgeschwächte Milzbrandbacillen genommen. 22 Stunden nach der Impfung lag die Hälfte der Bacillen in Zellen; sowohl unter diesen wie unter den frei liegenden befanden sich degenerirte Formen. Nach 64 Stunden wurden nur noch wenige Bacillen, darunter immer noch frei liegende gefunden. Die Leukocytenansammlung war stets bedeutend. In der zweiten Versuchsreihe wurden in derselben Weise virulente Milzbrandbacillen eingeführt; fanden sich unter diesen viele Involutionsformen, so wurden sehr viele Leukocyten in der Umgegend des Röhrchens gefunden; zwischen und in diesen lagen vielfach degenerirte Bacillen. Im Serum, welches das Gewebe um das Röhrchen durchtränkte, wucherten die Bacillen sehr üppig. - Wurden nur lebenskräftige Bacillen eingebracht, so war die Leukocytenansammlung um das Röhrchen geringer; es degenerirten nur wenige Bacillen, und auch diese nur extracellulär.

Rogowitsch (48) impfte Thiere mit virulentem und abgeschwächtem Rauschbrand. Der abgeschwächte Rauschbrand vermehrte sich im Thierkörper übẹhaupt nicht; der virulente verursachte bei empfänglichen Thieren starkes Exsudat und Blutungen und die Bacillen drangen in das Gewebe vor. Bei immunen Thieren blieben die Bacillen auf die Infectionsstelle beschränkt, die ausserordentlich dicht von Leukocyten umgeben war. Phagocytose war nirgends zu bemerken.

Metschnik off (34) fand, dass Milzbrandbacillen im Organismus der Taube zunächst nicht nur am Leben bleiben, sondern auch sich darin entwickeln; das Zugrundegehen kommt erst durch Phagocytose zu Stande. Es gelang ihm, mehrere Leukocyten, die Milzbrandbacillen enthielten, zu isoliren und durch Cultur nachzuweisen, dass die Bacillen noch am Leben - waren.

In einer weiteren Arbeit (35) constatirte er einerseits, dass die weissen Ratten nicht immun gegen Milzbrand sind; ferner, dass sich selbst abgeschwächte Milzbrandbacillen in der weissen Ratte entwickeln. Bleibt der Process local, so kommt die Heilung durch Phagocytose zu Stande; doch ist diese auch bei tödtlich verlaufenden Fällen zu bemerken.

$\mathrm{Ruffer}(49,50,51)$ inficirte Meerschweinchen mit virulenten Rauschbrandbacillen. Nach 12 Stunden waren an der Infectionsstelle enorme Mengen von Bacillen, die Leukocyten spärlich, die Phagocytose gering. Nach 48 Stunden waren viele Leukocyten vorhanden und die Phagocytose stark. Die Umgebung der Infectionsstelle besteht aus einem Wall dichtgedrängter Leukocyten und aus vielfach frei liegenden Stäbchen; weiter im Gewebe findet man nur noch frei liegende Leukocyten und keine Stäbchen 
mehr. Die Auswanderung der Wanderzellen nach der Impfstelle ist der Zahl der eingeführten Mikroorganismen umgekehrt proportional. Ferner fand er, dass, wenn man Milchsäure dem Vaccin zufügt, die Thiere immer sterben, da Milchsäure auf die Leukocyten negativ chemotactisch wirkt.

Lubarsch (26) fand, dass bei Tauben die Phagocytose um so bedeutender ist, je widerstandsfähiger das Individuum ist. Bei Ratten fand er gewaltige Leukocytenauswanderung und oft ausgedehnte Nekrosen; Phagocytose wurde nie vermisst. Auch bei Katzen, die empfänglich sind, war sie sehr bedeutend und nahm mit der Dauer der Infection ab. Bei Hunden wurde niemals ein Auswachsen der Sporen beobachtet; das Exsudat an der Infectionsstelle hatte einen eitrigen Charakter. Viele Sporen lagen intracellulär; doch wurden auch noch nach 48 Stunden zahlreiche ausserhalb der Zellen gesehen. Beim Menschen geht die Phagocytose dem Verlaufe des Milzbrandes und dem Untergang der Bacillen parallel. Bei Impfung ron Hammeln mit abgeschwächtem Material hatte Lubarsch dieselben Resultate wie Bitter, nur wurden viel häufiger intracellulär liegende Bacillen gefunden, was $L u b a r s c h$ auf seine dünneren Schnitte zurückführt. Er sieht in der Phagocytose keine wesentliche Ursache der Immunität, sondern glaubt, dass sie nur hier und da von Bedeutung für die Vernichtung der Bakterien ist, wenn dieselben bereits extracellulär geschädigt sind.

Netschajeff (37) tränkte Schwämme mit Milzbrandbacillen, die er mit Methylenblau lebend gefärbt hatte und führte sie den Versuchsthieren subcutan ein. Bei Mäusen und Meerschweinchen wurde keine Ansammlung von Leukocyten bemerkt; bei Kaninchen war sie gering und keine Phagocytose vorhanden; bei Hunden war sie ziemlich häufig, während sie bei Vögeln selten gesehen wurde.

Vaillard und Vincent (60) beobachteten, dass von Tetanusgift befreite Tetanussporen und -bacillen keinen Tetanus hervorrufen. Sie füllten Ziegler'sche Kammern oder. Watte mit denselben und brachten sie Kaninchen subcutan bei. Es entwickelte sich sehr lebhafte Phagocytose, die schon nach 18 bis 24 Stunden zur vollständigen Vernichtung der Sporen führte. Brachten sie gleichzeitig Milchsảure ein, so waren nur sehr wenig Leukocyten sichtbar und die Sporen keimten zu Stäbchen aus. Auch wenn sie gleichzeitig Prodigiosus mit einführten, wurden die Sporen nicht aufgenommen; wie die Verff. glauben, weil jener die Leukocyten stärker anzieht. Capillaren mit Tetanustoxin hatten eine abstossende Wirkung auf die Leukocyten.

Trapeznikoff (58) stellte Untersuchungen über das Schicksal der Sporen im Organismus an. Die Untersuchung geschah an Ausstrich- 
BEITRÄGE ZUR LEeRE VON DER NATÜRLICHEN IMMUNität. I. 7

präparaten. Milzbrandsporen wurden im Organismus des Huhnes sehr schnell von Leukocyten aufgenommen; doch waren noch nach 44 Stunden freie vorhanden. Die Sporen blieben 6 Tage am Leben und virulent; nach 14 Tagen waren sie abgestorben. Bei abgekühlten Thieren keimten sie Anfangs aus und wurden erst später phagocytirt. Auch in Tauben keimten sie aus und warden erst dann oder auch schon vorher von den Leukocyten aufgenommen. Bei Kaninchen und Meerschweinchen waren nach 3 Stunden nicht viele Leukocyten an der Infectionsstelle vorhanden, doch hatten diese viele Sporen aufgenommen; selten fanden sich Bacillen in Zellen. Nach 24 Stunden waren noch immer wenige Leukocyten vorhanden; die Zahl der Bacillen hatte bedeutend zugenommen.

Alexander-Lewin (3) studirte das experimentelle Milzbrandödem an Meerschweinchen und weissen Ratten. Schon nach 4 Stunden war dasselbe bemerkbar und es waren Leukocyten vorhanden; die Lagerung zu den Bacillen war sehr verschieden,- der Ribbert'sche Grenzwall oft durchwachsen. Phagocytose wurde nicht bemerkt. Vom zweiten Tage ab degenerirten die Bacillen schleimig. Die Versuche mit Staphylokokken führten zu denselben Resultaten wie sie Hohnfeldt in seiner oben erwähnten Arbeit hatte.

Silvestri (56) wies nach, dass bei der Impfung von Staphylokokken in die Hornhaut des Kaninchens die Kokken lebend von den Leukocyten aufgenommen werden; auch wenn alle Kokken aufgenommen waren, liessen sich noch Culturen erhalten, die allerdings 24 Stunden nach der Impfung abgeschwächt waren.

Liakhovétsky (25) impfte Milzbrandbacillen auf die Hornhaut von Kaninchen und Hunden. Bei den Thieren, die gegen Milzbrand widerstandsfähig waren, gingen die Bacillen extracellulär zu Grunde; doch wurden auch oft normale aufgenommene Bacillen gefunden.

Mesnil (32) inficirte mit Vibrio Metschnikoff Meerschweinchen, die verschieden empfänglich dagegen sind. Bei denen, die schnell starben, beobachtete er keine oder fast keine Phagocytose; je später der Tod eintrat, desto stärker war die Phagocytose. Fine extracelluläre Zerstörung findet nicht statt. Auch beim Huhn gehen die Vibrionen nur durch Phagocytose zu Grunde.

Unna (59) kommt in einer Arbeit über die Einwanderung der Staphylokokken in die menschliche Haut zu folgenden Schlüssen: Die von den Staphylokokken chemotaktisch angezogenen Leukocyten sterben in der Nähe ersterer $a b$, ohne dieselben in sich aufgenommen zu haben. Wo in das menschliche Hautgewebe Staphylokokken eingedrungen sind, findet man sie von einem Leukocytenwall umgeben. Wo um einen Staphylokokbeneinbruch sich in der Haut rasch und leicht ein dichter Leukocyten- 
wall ausbilden kann, trägt der Process nur den Charakter einer einfachen Leukotaxis; wo die Ausbildung des Walles auf Schwierigkeiten stösst, bilden sich die vier Cardinalsymptome der Entzündung aus.

Afanassieff $(1,2)$ fand, dass Bakterien, die auf das unbeschädigte Granulationsgewebe aufgebracht werden, nicht in die inneren Organe eindringen. Die Bakterien werden nach 4 bis 12 Stunden in ihrer Virulenz abgeschwächt; nach längerer Zeit zerfallen sie extracellulär.

Noetzel (38) hatte mit Bakterien dieselben Resultate; er constatirte ferner, dass auch eine Resorption von Tetanusgift durch die granulirende Fläche nicht stattfindet.

Podbelsky (43) injicirte Kaninchen Subtilissporen subcutan; sie wurden besonders von mononucleären Leukocyten aufgenommen, doch waren auch noch nach längerer Zeit einige frei. Auskeimen wurde nicht beobachtet. Sporen, die längere Zeit in activem Serum fortgezüchtet waren, keimten im Unterhautzellgewebe aus und wurden dann von den Leukocyten aufgenommen.

Martel (28) fand bei seinen Versuchen über den Milzbrand des Hundes, dass die Phagocytose bei empfänglichen Thieren gering, bei immunen Thieren stark ist; in letzterem Falle waren sehr viele Leukocyten an der Infectionsstelle.

Radziewsky (45) untersuchte das Verhalten des Pneumococcus im Unterhautzellgewebe des Kaninchens. Es bildete sich nach einigen Stunden eine weiche teigige Geschwulst, die eine seröse Flüssigkeit enthielt. Nach 5 Stunden fanden sich Degenerationsformen, Kapseln mit Kokkenresten und ror allem leere Kapseln. Die Bakterienzerstörung fand nur extracellulär statt.

Etwas andere Verhältnisse als bei der subcutanen Infection liegen bei der Injection in die Bauchhöhle vor. Dieselben sind theils zur Untersuchung günstiger, da die Entnahme einfacher ist, andererseits bieten sie wieder Complicationen, die nicht erlauben, die dortigen Vorgänge ohne Weiteres zur Erklärung der Vorgänge bei subcutaner Infection zu benutzen.

Netschajeff (37) brachte lebend gefärbte Milzbrandbacillen zwischen zwei Deckgläsern Hunden und Kaninchen in die Bauchhöhle. Er beobachtete, dass bei älteren Hunden die Bacillen intracellulär, aber auch vielfach extracellulär $z$ wischen den Lenkocyten zerfallen, während bei jungen Hunden und Kaninchen kein Zerfall stattindet.

$\mathrm{Zu}$ diesen Versuchen bemerkt Vejnar (61), dass ein intracellulärer Zerfall der Milzbrandbacillen nicht erwiesen sei, da gleichzeitig gelöstes Methylenblau eingebracht worden sei und die Leukocyten auch aus Methylenblaulösungen den Farbstoff in Körnchen aufnehmen könnten. 
Metschnikoff (36) injicirte Choleravibrionen in das Peritoneum des normalen Meerschwëinchens. Es trat zunächst Hypoleukocytose und Zerstörung der weissen Blutkörperchen, Phagolyse, ein; die Vibrionen schwammen frei in der Flüssigkeit herum. Mit der Zunahme an Leukocyten nahm auch die Phagocytose zu, bis nach 8 Stunden sämmtliche Vibrionen phagocytirt waren; doch waren noch nach 24 Stunden Vibrionen zu züchten.

Bordet (9) arbeitete mit hochvirulenten Streptokokken. Gleich nach der Injection waren die Leukocyten selten; nach 1 Stunde häufiger, nach 3 Stunden von grösserer Zahl als nöthig waren, um alle Kokken aufzunehmen. Die nicht aufgenommenen Kokken vermehrten sich nun; ihre Abkömmlinge waren meist diplokokkenförmig und von einer Kapsel umgeben. - Nach 6 Stunden waren die Leukocyten fast sämmtlich leer es wurden keine Kokken aufgenommen, obwohl sie in directem Contact mit ihnen lagen, und die Leukocyten lebhafte amöboide Bewegungen zeigten. Es war also durch Selection eine virulente Rasse von Streptokokken entstanden, indem die avirulenten phagocytirt worden waren. Injicirte er jetzt dem Kaninchen Proteusbacillen, so wurden diese phagocytirt, ein Zeichen, dass die Aufnahmsfähigkeit der Leukocyten nicht vermindert war. Auch viele andere Bakterien wurden von den Leukocyten aufgenommen; sie färbten sich dann mit Eosin, was ein Zeichen des Absterbens ist.

Schattenfroh (53) fand, dass Hefezellen, die er Kaninchen und Meerschweinchen in die Bauchhöhle injicirte, dort schon nach 1 bis 2 Stunden im Innern der Leukocyten zu Grunde gingen. Actives Serum hatte keine hefetödtende Wirkung, ebensowenig Leukocytenextract. Stark pathogene Bakterien gingen durch Alexinwirkung bei extravasculären Versuchen zu Grunde, während bei ihnen intraperitoneal die Phagocytose mässig oder gar nicht vorhanden war.

Durham (17) studirte den Mechanismus der Reaction auf intraperitoneale Injection. Zunächst tritt Hypoleukocytose auf, die aber weniger durch Zerstörung der Leukocyten, als durch Anhaften an der Bauchwandung bedingt ist. Schon nach 1 Stunde nahmen die Leukocyten wieder zu und überschritten bald die Zahl der vorher vorhandenen. Extracelluläre Zerstörung der Bakterien kann stets beobachtet werden.

Dagegen behauptet Pieralini (42), dass allerdings eine Ansammlung der Leukocyten an den Wandungen der Bauchböhle stattfinde, dass aber unter diesen Leukocyten sich durch Färbung viele als zerstört oder geschädigt nachweisen liessen. „Präparirt" man die Bauchhöhle durch eine Injection 24 Stunden rorher, so tritt bei der zweiten Injection diese Zerstörung nicht ein. 
Bordet (10) injicirte Meerschweinchen hochrirulente Streptokokken. Nach einer kurz dauernden Phagolyse traten viele polynucleäre und mononucleäre Leukocyten auf. Wurde eine nicht tödtliche Dosis injicirt, so phagocytirten diese sämmtliche Kokken; wurde eine tödtliche Dosis injicirt, so blieben zahlreiche Kokken frei, umgaben sich mit einer Kapsel und wurden auch weiterhin nicht phagocytirt. Bei dem noch empfänglicheren Kaninchen wurden auch Anfangs nur sehr wenige Streptokokken aufgenommen.

Sawtschenko (52) fand, dass die Ratten, mit denen er arbeitete, für Milzbrand höchst empfänglich waren, selbst für das 1. Vaccin. Intraperitoneal injicirt dagegen gehen die Bacillen zum grössten Theil nach kurzer Zeit extracellulär zu Grunde; die Ueberlebenden bilden eine Kapsel um sich und widerstehen dadurch den schädlichen Einflüssen des Körpers.

Marchand (27) constatirte, dass abgeschwächte Streptokokken leicht von den Leukocyten aufgenommen werden, während es bei virulenten-so gut wie gar nicht zu einer Phagocytose kommt.

Wassermann (63) injicirte Kaninchen eine an sich nicht tödtliche Dosis von Typhusbacillen und gleichzeitig Antialexin; die Thiere starben, während die Controlthiere am Leben blieben.

Besredka (6) führt diese Wirkung des Antialexins vor Allem auf Sehädigung der phagocytären Funktionen der Leukocyten zurück.

Radziewsky $(44,45)$ wandte bei seinen Untersuchungen eine neue Technik an, indem er die Präparate mit 30 fach verdünnter Carbolfuchsinlösung 1 Stunde lang färbte. Es kamen hierdurch Zerfallsformen von Bakterien zum Vorschein, die auf gewöhnliche Weise nicht färbbar waren. Er injicirte Choleravibrionen, Pyocyaneus, Typhus, Streptokokken und sehr schwach virulenten Milzbrand in die Bauchhöhle; stets war Hyperleukocytose vorhanden, doch die Phagocytose ohne Bedeutung. Die Bakterien vermehren sich, wenn sie in genügender Anzahl eingeführt sind; mit dieser Vermehrung geht ein Absterben parallel, das theils in Form des Pfeiffer'schen Phänomens stattfindet, theils in der Art, dass die Bakterien kleiner und dünner werden, um auf diese Weise zu verschwinden. Dieser Untergang findet im Verlauf der Krankheit in stärkerem Maasse statt als im Beginn; es geht daraus hervor, dass der Organismus sich während der Infection gegen die Mikroben bis zu einem gewissen Grade immunisirt.

Zilberberg und Zeliony (66) suchten die Arbeit von Werigo zu widerlegen, der behauptete, dass er nach intravenöser Injection niemals negative Chemotaxis gefunden hätte. Sie fanden, dass von der Phagocytose nur avirulente Bakterien betroffen werden, die immer in Culturen auf künstlichen Nährböden vorhanden sind; wenn sie Hühnercholerabacillen 
BEITRÄGE ZUR LEHRE VON DER NATÜRLICHEN IMTMUNITÄT. I. 11

einem Kaninchen in die Bauchhöhle injicirten und nach einiger Zeit das Exsudat einem anderen Kaninchen beibrachten, so wurden die Bakterien nicht mehr phagocytirt, weil nur virulente Bacillen am Leben geblieben waren; dagegen wurden andere gleichzeitig eingebrachte avirulente Kokken oder Hühnercholerabakterien von künstlichen Nährböden phagocytirt.

Wallgren (62) fand bei seinen Arbeiten über peritoneale Infection mit Streptokokken, dass der Schutz der Bauchhöhle bedingt ist durch ihre grosse Resorptionsfähigkeit, durch die Thätigkeit der anwesenden und zuströmenden Leukocyten und vielleicht durch die Endothelzellen des Peritoneums. Die Leukocyten tragen durch die Phagocytose, durch ihre Zerfallsproducte und vielleicht auch durch ihre Secretionen zur Bekämpfung der Streptokokken bei. Die Phagocytose ist bei Versuchen mit virulenten Streptokokken hauptsächlich am Anfang, bei Versuchen mit schwach virulenten, während der ganzen Dauer des Infectionsprocesses vorhanden. Die Streptokokken können auf die Leukocyten zerstörend einwirken.

Von den Versuchen, die mittels intravenöser Injection angestellt wurden, sind vor Allem die von Ribbert im Stande, eine Erklärung auch für die Verhältnisse bei cutaner Injection zu geben. Ribbert (46) fand, dass die Sporen pathogener Schimmelpilze, sobald sie zu wachsen beginnen, durch eine Ansammlung dicht gedrängter Leukocyten entweder schon am Auskeimen gehindert oder wenigstens in ihrem weiteren Wachsthum erheblich eingeschränkt werden. Es bilden die Leukocyten einen Wall um sie herum, der ein allgemeines Durchwachsen des Körpers verhindert. Wo dieser Process langsam vor sich geht, wie in der Niere, wachsen auch die Pilze zu längeren Fäden aus. In derselben Weise gehen manche Bakterien zu Grunde, und zwar zum Theil durch Hinderung des Wachsthums, so lange die Bakterien extracellulär liegen, zum grössten Theil durch Phagocytose oder durch eine Combination beider Vorgänge.

Bei der grossen Wichtigkeit, die nach den meisten der im Vorstehenden erwähnten Arbeiten den Leukocyten zukommt, seien hier auch die Arbeiten erwähnt, die sich mit den Eigenschaften derselben beschäftigen, soweit sie für den Infectionsprocess von Bedeutung sind.

Vor Allem kommen hier die Arbeiten von Leber in Betracht, die zuletzt in dem klassischen Werke: „Die Entstehung der Entzündung" gesammelt erschienen sind. Die meisten Versuche stellte Leber an der Hornhaut an, also einem gefässlosen Organe, an dem die Zuwanderung der Leukocyten am besten beobachtet werden kann und schon makroskopisch deutliche Resultate ergiebt.

In dem ersten Theile der Arbeiten untersuchte er die durch Aspergillus fumigatus in der Hornhaut hervorgerufene Erkrankung. Injicirte Aspergillussporen keimen dort aus und wuchern nach allen Seiten in die 
Hornhaut hinein. Nach kurzer Zeit bildet sich eine erst sichel-, dann ringförmige Ansammlung von Leukocyten, die allmählich zur Einschmelzung und Abstossung der inficirten Partie führte. Die Pilze wucherten niemals über den Infiltrationsring hinaus, selten wenige in ihn hinein; andererseits hört aber auch der Ring am Rande des durch die Pilzeinwirkung nekrotisch gewordenen Gewebes auf. Nur bei geringer Wachsthumsenergie der Sporen wurde das Mycel von den Leukocyten eingehüllt. Am inneren Rande des Ringes waren die Leukocyten zu Grunde gegangen. Die Zuwanderung der Leukocyten ist nur so zu erklären, dass die Pilze durch ihr Wachsthum Stoffe erzeugen, welche weithin diffundirten und Exsudation und Emigration veranlassten; in der Nähe des Herdes bewirkten diese Stoffe durch ihre stärkere Concentration dann Lähmung der Leukocyten, wie sie vorher Nekrose des Hornhautgewebes in ihrer directen Umgebung verursacht hatten.

Dieselben Verhältnisse lagen bei Infeetion mit Staphylokokken. vor: erst Wuchern der Kokken, dann Bildung eines Leukocytenwalles. Phagocytose wurde selten beobachtet; dieser Unterschied von den oben erwähnten Beobachtungen von Hess (22) wird so erklärt, dass Hess weniger Kokken einbrachte und in Folge dessen die Leukocyten zu diesen vordringen konnten.

Eine ähnliche Wirkung, wie lebende Pilze und Kokken, hatten keimfreie Filtrate und abgetödtete Culturen.

Weitere Untersuchungen waren der Frage gewidmet, welche andere Substanzen leukocytenanlockend wirkten. Es zeigte sich, dass dies nicht nur bei den stark entzündungserregenden, den Acria, der Fall war, sondern auch bei anscheinend ganz unlöslichen oder schwer löslichen, wie Gold, Silber, Kupfer, Blei, Quecksilber. Da eine Fernwirkung dieser Stoffe nicht anders als auf chemischem Wege denkbar ist, so ist anzunehmen, dass dieselben, wenn auch nur in geringem Maasse, in den alkalischen Körpersäften in Lösung gehen.

In der gleichen Weise riefen gepulverte Stoffe, die für ganz indifferent gelten, wie Zinnober, Gold, Platin, Baryumsulfat, Graphit, Emigration hervor und wurden von den Leukocyten aufgenommen, was ebenfalls der Chemotaxis zuzuschreiben ist.

Der letzte Abschnitt handelt über die eitrige Erweichung und Gewebsschmelzung. Dieselbe wird nicht durch die Mikroorganismen, sondern durch die Leukocyten hervorgerufen.

Leber ist der Ansicht, dass die Entzündưng und Eiterung einen für den Körper nützlichen Process darstelle. Was die Phagocytose betrifft, so ist sie rasch und vollständig, wenn kein Wachsthum stattfindet; bei mässiger Entwickelung ist sie unvollständig, und bei sehr kräftiger ist die 
Giftbildung so stark, dass die Leukocyten in einigem Abstande von dem Herde untergehen, ohne an ihn heranzukommen; deshalb sei sie auch nicht als hauptsächliche Schutzvorrichtung des Körpers zu betrachten.

Kurz nachdem die Arbeiten von Leber erschienen waren, beschäftigten sich Massart und Bordet (30) mit der Frage der Reizbarkeit der Leukocyten. Sie unterscheiden eine tactile und eine chemische. In Folge der ersteren suchen die Leukocyten auf der Fläche, auf der sie sich bewegen, einen möglichst grossen Raum einzuuehmen; in Folge der letzteren wandern sie auf anlockende Stoffe zu. Die Bewegungen der Leukocyten des Frosehes können sowohl im hängenden Tropfen durch Zugabe von Chloroform als auch im lebenden Thiere durch Narkose aufgehoben werden; im letzteren Falle tritt, wie man an dem aufgespannten Mesenterium beobachten kann, nur Randstellung, aber keine Emigration ein.

Buchner (11) stellte aus verschiedenen Bakterien Stoffe dar, die auf die Leukocyten chemotactisch wirkten. Wurden dieselben in Capillarröhrchen gebracht, so fanden sich nach einigen Tagen mehrere Millimeter lange Pfröpfe an ihrem freien Ende, die aus Iseukocyten bestanden. Stoffwechselproducte ron bekannter Constitution hatten diese Eigenschaft nicht.

Gabritschewsky (20) untersuchte mittels Capillarröhrchen chemische Stoffe auf ihre chemotactische Wirksamkeit beim Frosch und beim Kaninchen. Von Bakterien wirkte nur Hühnercholera in 24 stündigen Culturen chemotactisch negativ, die übrigen (Pyocyaneus, Typhus, Staphylococcus, Prodigiosus, Milzbrand, Schweinerothlauf) chemotactisch positiv.

Massart und Bordet (31) fanden in einer weiteren Arbeit, dass bei Thieren, denen sie Bakterienculturen in das Blut injicirt hatten, bei gleichzeitiger subcutaner Infection kein Zuwandern von Leukocyten eintritt, da schon im Blute chemotactisch wirkende Stoffe circuliren.

Massart (29) brachte Culturen von Milzbrand, Schweinecholera, Schweinrothlauf, Vibrio Metschnikoff, Hühnercholera, Diphtherie in Glascapillaren in die Bauchhöhle von Kaninchen, Meerschweinchen und Tauben ein. Nach 7 Stunden waren - mit Ausnahme der Diphtheriecultur die Leukocytenpfröpfe um so kürzer, je virulenter die Cultur war. Verdünnungen der abstossend wirkenden Culturen bewirkten Anlockung. Das Beispiel der Diphtherie zeigt, dass die negativ chemotactisch wirksamen Stoffe nicht identisch sind mit den spezifisch toxischen. - Bei immunisirten Thieren wirkten die Culturen, gegen die das Thier immunisirt war, anlockend auf die Leukocyten.

v. Sicherer (54) brachte in von Kaninchen steril gewonnenen Eiter Capillaren, die er mit verschiedenen Stoffen gefüllt hatte. Stark anlockend wirkten Hefenextract, abgetödtete Typhus- und Pyocyaneusbacillen, Glutencaseïn u. s. w., weniger stark lebende Typhuscultur. Frei von Leukocyten 
blieben die mit physiologischer Kochsalzlösung und die mit Sublimat, Milchsäure und ähnlichem gefüllten Röhrchen.

Gegen Pfoehl (41), der andere Resultate hatte, hebt er nach Wiederholung seiner Versuche hervor (55), dass die mikroskopische Untersuchung der gebildeten Pröpfe nöthig ist, da sie sich auch scheinbar in mit negativ chemotactischer Substanz gefüllten Röhrchen (Sublimat) vorfinden, dann aber nicht aus Leukocyten, sondern aus Fibrin bestehen.

Almquist (4) centrifugirte Leukocyten, denen er Bakterien zugefügt hatte. Die Leukocyten nahmen zahlreiche Bakterien auf, selbst dann noch, wenn sie auf $15^{\circ}$ abgekühlt waren.

Ferner sind hier die Arbeiten zu erwähnen, die beweisen, dass auch andere Körper, wie rothe Blutkörperchen, Spermatozoen u. s. w. von den Leukocyten aufgenommen werden. Dass sich der Schutz durch Leukocyten uicht nur auf Bakterien erstreckt, zeigte Besredka (7), indem er Thieren eine Emulsion von Arsentrisulfid in die Bauchhöhle injicirte. Dasselbe wurde durch mononucleäre Leukocyten aufgenommen und die Thiere blieben am Leben. Wurde gleichzeitig Carmin injieirt oder das Arsentrisulfid in Collodiumsäckchen in die Bauchböhle eingebracht, so starben die Thiere, da im ersteren Falle Hypoleukocytose vorhanden war, im letzteren Falle die Leukocyten nicht an das Gift herankommen konnten und dasselbe sich in eine lösliche Modification umwandelte. -

Bei den verschiedenen Resultaten der angeführten Versuche erschienen neue Versuche gerechtfertigt, die zur Lösung der Frage beitragen sollten, warum die einen Bakterien pathogen wirken, die anderen nicht. Die Versuche schliessen sich am einfachsten an die gewöhnlichste Art der natürlichen Infection an, nämlich der Infection durch die Haut. Intraperitoneale Infection mit Bakterien kommt in praxi verhältnissmässig selten vor, so dass Versuche damit an sich von geringerem Interesse sind; wichtiger wären sie, wenn dadurch einfachere Verhältnisse geboten würden als bei der subcutanen Infection und man die dabei gefundenen Thatsachen auf diese übertragen könnte. Doch haben die vorher angeführten Versuche ergeben, dass im Gegentheil die Verhältnisse auch hierbei äusserst complicirt sind und wir sie auf jeden Fall nicht ohne Weiteres auf Hautinfectionen übertragen dürfen.

Es wurden also bei weissen Mäusen Hautwunden mit verschiedenen Bakterien inficirt. Als Typus der hochgradig pathogenen wurden Milzbrandbacillen, Pneumokokken und Scbweinerothlaufbacillen gewählt; als Typus von Bacillen, die für andere Thiere, aber nicht für die weisse Maus pathogen sind, Staphylokokken und Tuberkelbacillen; als Typus der Bacillen, die überhaupt nicht für Wirbelthiere pathogen sind, Heubacillen und gelbe Sarcinen. Ferner wurden Wunden mit Zinnober inficirt, um 
das Verhalten des Organismus gegen eine fast reizlose Substanz mit dem gegen Bakterien zu vergleichen. - Die Untersuchung der Wunden kann nur dann genau sein, wenn sie an Schnittpräparaten geschieht. Ausstrichpräparate können kein Bild über die ganze Wunde geben; und ausserdem tritt die Lage der Bakterien zu den Zellen darin nicht hervor. Speciell über die Phagocytose ergiebt diese Cntersuchungsart gänzlich falsche Resultate. So wurde beispielsweise eine Maus an zwei symmetrischen Stellen mit nicht pathogenen Bakterien inficirt und nach 24 Stunden getödtet. Bei der Untersuchung im Ausstrichpräparate schien es, als ob fast sämmtliche Bakterien extracellulär lägen; bei der Untersuchung im Schnitt dagegen wurden nur intracelluläre gefunden. Speciell wenn das Material schon etwas eingetrocknet ist - was schon nach sehr kurzer Zeit geschieht - , ergiebt die Untersuchung im Ausstrichpräparate ein vollständig verzerrtes Bild.

Die Technik der Versuche gestaltete sich also folgendermaassen:

\section{Technik.}

Zur Infection wurden weissen Mäusen von ungefähr gleicher Grösse Schnitte am seitlichen unteren Theile des Rückens, nahe über dem Oberschenkel mit einem inficirten Messer beigebracht und noch mehr Cultur in die Wunde gestrichen. Die Schnitte wurden in der Längsrichtung des Körpers angelegt; die Tiefe war verschieden. Vorher wurden die Haare möglichst kurz geschnitten; die Haut wurde nicht mit einem Desinfectionsmittel behandelt, da der normale Infectionsweg möglichst getreu nachgeahmt werden sollte und jedes Reiben der Haut darin gestört hätte. Ein Eindringen von Haaren in die Wunde war selten, da die Schnitte in der Richtung ihres Wachsthums geführt wurden; es war in den Schnittpräparaten selbstverständlich leicht nachzuweisen; solche Schnitte wurden ron der Beurtheilung ausgeschaltet. Die Culturen waren, wo nicht anders erwähnt, 24 stündige Stricheulturen auf Agarplatten; das Messer wurde damit mit grösster Vorsicht durch Darüberstreichen inficirt, um jedes Mitnehmen von Agar zu vermeiden. - In bestimmten Abständen wurden die Thiere getödtet und die Haut und das darunter liegende Gewebe bis in die Bauchhöhle losgesehnitten. Die Fixation geschah theils in Alkohol, theils in Sublimat; letzteres hat den Vorzug, dass sich die histologischen Einzelheiten bedeutend besser erhalten, ersterer, dass sich wegen der schnelleren Härtung keine Partikelchen - Blutcoagula in der Wunde u. s. w. - ablösen. Die Einbettung geschah in Paraftin, die Schnittdicke war $15 \mu$. Von jeder Wunde wurden Stufenschnitte in der Weise angefertigt, dass von einer Stelle fünf Schnitte auf fünf Deckgläser aufgeklebt wurden; dann wurde ein Stück beim Schneiden übergangen; dann wieder fünf Schnitte 
auf dieselben fünf Deckgläser gebracht u. s. w. Das Aufkleben geschah mit Wasser. Auf diese Weise war es möglich: 1. gleiche Stellen der Wunde in verschiedener Weise zu färben; 2. über alle Theile der Wunde einen Ueberblick zu erhalten.

Die Färbung geschah stets mit Lithioncarmin und nach Gram, wodurch die Zellen besser hervortraten, und mit Bismarckbraun und nach Gram, wodurch die Bakterien und ihr Verhalten zu den Zellen besonders deutlich wurden. Ferner wurden manche Schnitte, wo es nöthig schien, mit Hämatoxylin gefärbt; anch Gram-Methylgrün-Eosin ergab gute Bilder, die aber nicht haltbar waren. Färbung mit Methylenblau wurde nur selten angewendet; sie hat den Nachtheil, dass sich die Körnchenzellen in der Haut in einer Weise färben, dass sie nur schwer von Kokken zu unterscheiden sind.

Bei der Durchsicht der Präparate wurde oft das sehr intensive Licht einer elektrischen Mikroskopirlampe verwendet; es kamen dann manchmal noch Bakterien zum Vorschein, wo vorher in Folge der dichten Anhäufung der Zellen keine zu sehen waren.

Im Ganzen wurden gegen 2000 Schnittpräparate untersucht, von denen viele mehrere Schnittwunden zeigten.

Zur Anatomie der Haut der Maus seien folgende Vorbemerkungen gemacht: Auf die Epidermis mit dem Corium folgt eine ungefähr ebenso dicke Lage Fettgewebe; unter dieser liegt der ziemlich dünne Hautmuskel; dann folgt eine in den meisten Fällen sehr beträchtliche Bindegewebsschicht und darauf die Musculatur. Nur am vorderen Ende des Hautschnittes waren die Verhältnisse etwas anders, indem auf den Hautmuskel nur eine dünne bindegewebige und darauf wieder eine Fettschicht kam.

Mit „oben" soll im Folgenden immer "näher an der Obertläche"; mit ,unten" die entgegengesetzte Richtung bezeichnet werden.

Bei der Betrachtung der Schnitte fand sich, dass das Aussehen derselben ein verschiedenes ist - abgesehen von der Zeit, nach der die Thiere getödtet wurden -, in gewissen Fällen nach der Art der eingebrachten Bakterien und vor Allem nach der Tiefe der Wunde. Es sollen daher auch im Folgenden die Präparate zuerst nach dem ersten, dann nach dem zweiten Gesichtspunkte besprochen werden.

\section{Betrachtung nach der Art der eingebrachten Bakterien.}

Staphylokokken.

Da die Staphylokokken als Typus eines für die Maus schwach oder fast gar nicht pathogen wirkenden Mikroorganismus untersucht werden sollten, so wurde zu den Infectionen ein alter, schon seit Jahren in der 
BeITRÄGE ZUR LEHRE VON DER NATÜRLICHEN IMMUNITÄT. I. 17

Sammlung des Institutes fortgezüchteter Stamm gewählt. 1/5 Agarcultur intraperitoneal tödtete weisse Mäuse in 3 Tagen; nach intraperitonealer Injection von $1 / 10$ Agarcultur wurden sie schwer krank, erholten sich aber wieder.

Die Untersuchung der Schnitte, die in der angegebenen Weise nach Gram und mit Lithioncarmin bezw. Bismarckbraun gefärbt wurden, ergab folgende Resultate:

Nach 2 Stunden. Im Schnitte liegen, theils in grösseren Häufchen, theils mehr einzeln, zahlreiche Kokken. Die meisten liegen noch in der Wunde selbst, theilweise im Blutcoagulum, theilweise am Rande der Wunde; ein kleiner Theil ist auch schon seitlich und nach unten auf eine kurze Strecke in's Gewebe eingedrungen. Die Grösse der Kolkken ist verschieden: Im Coagulum und am Wundrande, besonders da, wo die Kokken in dichten Haufen liegen, sind die einzelnen Individuen klein; wo sie dagegen einzeln liegen, also vor Allem bei sämmtlichen eingedrungenen, aber auch am Wundrande und im Coagulum, sind sie bedeutend grösser und haben etwa den doppelten Durchmesser. Doch sind die grossen Kokken viel geringer an Zahl als die kleinen. Die Lagerung der Kokken zu einander zeigt ein charakteristisches Bild: Die kleinen Kokken liegen regellos, etwa so, wie man es. im Ausstrich einer Agarcultur sieht; die grossen liegen fast sämmtlich in Paaren, manche auch in Tetradenform; selten liegen sie einzeln und niemals in Häufchen.

Nach 4 Stunden. Die Kokken sind etwas weiter in's Gewebe eingedrungen als vorher, befinden sich aber bei mitteltiefen Schnitten (die im Fettgewebe enden) noch in der Nähe der Wunde, während sie bei tiefen (die bis auf das Bindegewebe gehen), bedeutend weiter weggeschwemmt sind. Die kleinen Kokken sind jetzt fast nur noch im Coagulum vorhanden, wo sie sehr dicht liegen; die Zahl der grossen Kokken dagegen hat bedeutend zugenommen. Sie liegen jetzt in Paaren, 'Tetraden oder selten auch in kleinen Häufchen zusammen.

Um die Wunde hat sich ein Wall von Leukocyten gebildet; auch in diesem bis zu seinem äusseren Rande befinden sich viele Kokken; dieselben sind besonders da, wo sie mehr einzeln liegen, phagocytirt. Die weiter in's Gewebe hineingeschwemmten Kokken sind sämmtlich gross und liegen meist in Paaren, Tetraden und Häufchen. Sie liegen alle auf dem Wege, auf dem die Leukocyten zur Wunde herankommen; die am weitesten in's Gewebe eingedrungenen sind sämmtlich phagocytirt.

Nach 8 Stunden. Die in dichten Haufen liegenden Kokken sind noch immer klein; die anderen haben die Grösse und Lage wie vorher. Die Lage der Kokken zu den Leukocyten ist folgende: In den am Leitzchr. f. Hygiene. XLV. 
äussersten Rande des Schnittes an der Oberfläche der Haut liegenden Kokken dringen überhaupt keine Leukocyten vor. Die Lage zu den weiter im Gewebe liegenden wird durch den Umstand bestimmt, ob sich riele oder wenige Koliken an einer Stelle befinden. Zwischen die einzeln oder in kleinẹn Häufchen liegenden Kokken sind überall Leukocyten eingedrungen und haben die Kokken phagocytirt (Taf. II, Fig. 8). Liegen 'dagegen die Kolken in dichten Massen, so stehen die Leukocyten in Form eines Walles oder Ringes um sie herum in geringem Abstand (Taf. III, Fig. 13). Die über die Infectionsstelle hinaus gelangten Kokken sind sämmtlich phagocytirt.

Nach 12 Stunden. Dasselbe Bild wie vorher. (Taf. I, Fig. 2.)

Nach 24 Stunden. Auch jetzt sind noch neben den grossen Kokken kleine zu sehen, die im Coagulum in dichten Haufen liegen. In den Leukocyten liegen öfters Häufchen, doch meist einzelne Kokken oder. Kokkenpaare; dieselben sind gut färbbar.

Nach 7 Tagen. Auch bei tiefen Schnitten ist jetzt die Wunde überhäutet und die darin befindlichen Bakterien abgestossen. In dem Gewebe unter der neugebildeten Epidermis befinden sich mässig viele Leukocyten und wenige Kokken, die sämmtlich phagocytirt und vielfach kleiner und anscheinend im Zerfall begriffen sind.

$\mathrm{Nach} 14$ Tagen sind mikroskopisch keine Kokken mehr nachweisbar.

Um den Untergang der Staphylokokken zu studiren, wurde drei Mäusen je 1 Oese Agarcultur subcutan in eine Hauttasche beigebracht. Nach 1 Woche waren culturell viele orange und weisse Staphylokokken nachweisbar; nach 2 Wochen wuchsen wenige Colonieen von orange und weissen Staphylokokken; nach 3 Wochen war die Infectionsstelle steril.

\section{Milzbrand.}

Die Milzbrandbacillen waren ziemlich stark virulent; Mäuse starben bei subcutaner Infection nach 36 Stunden.

Untersuchung 2 Stunden nach der Infection: Die Milzbrandbacillen liegen theilweise im Schnitte, theilweise auf der Haut oder kleben an den Haaren. Einige sind auch in das Gewebe eingedrungen; doch nicht weiter als vorher die Staphylokokken nach der gleichen Zeit. Auch hier ist ein Unterschied in der Gestalt zu sehen: diejenigen Bacillen, die auf der Haut und in dichten Haufen in der Wunde liegen, erscheinen als mehr oder minder lange Fäden; diejenigen, die einzeln am Wundrande oder namentlich im Gewebe liegen, sind bedeutend kürzer; sie liegen oft zu zweien. Dies ist zwar nicht durchweg der Fall, doch überwiegen wenigstens die erwähnten Formen in den betreffenden Theilen bedeutend. 
Nach 4 Stunden. Die Bacillen sind etwas tiefer ins Gewebe eingedrungen; zugleich sind jetzt viele Leukocyten an die Wunde herangekommen. Diese haben die Bacillen theils in Form eines Walles umgeben, theils liegen sie zwischen ihnen. Auch jetzt sind Grössenunterschiede sichtbar: die frei im Gewebe und in einiger Entfernung von den Leukocyten liegenden Bacillen sind im allgemeinen klein, die ganz nahe den Leukocyten grösser und die im Leukocytenhaufen liegenden wachsen zu langen Fäden aus. Von den zwischen den Leukocyten liegenden sind wenige phagocytirt; sie liegen dann vielfach gebogen oder geknickt mit der concaven Seite nach dem Kerne zu. Viele andere liegen dicht an und zwischen den Zellen, die meisten in so grossem Abstande, dass eine Phagocytose sicher auszuschliessen ist.

Nach 8 Stunden. Das Coagulum ist voller Mrilzbrandbacillen; die von den Leukocyten umgebene Stelle der Epidermis zeigt viel weniger und nur in geringe Tiefe eingedrungene, so dass zwischen ihnen und den Leukocyten ein beträchtlicher Raum bleibt. In manchen Schnitten dagegen, besonders bei Infection in eine Ohrwunde sind die Bacillen über die Infectionsstelle weit hinaus vorgedrungen und in der Epidermis, im Corium und im subcutanen Gewebe zu sehen. Diese Bacillen sind meist kurz oder aus kurzen Stäbchen zusammengesetzte Ketten. Auch an anderen Schnitten, die bis in das Bindegewebe gehen, haben sie sich von hier aus weiter verbreitet und liegen theils in Lymphspalten, theils zwischen den Bindegewebsfasern. Von den Bacillen, die an der Infectionsstelle zwischen den Leukocyten liegen, sind manche phagocytirt, die meisten frei; die weiter in das Gewebe eingedrungenen sind sämmtlich frei, auch wenn Leukocyten in ihrer Nähe liegen.

Nach 12 Stund en. An der Wunde derselbe Befund. (Taf. III, Fig. 17.) Manche Leukocyten haben viele Milzbrandbacillen im Inneren, dagegen schlingen sich die meisten Bacillen zwischen den Leukocyten durch. Die tiefer in das Gewebe eingedrungenen Bacillen liegen in Häufchen und sind, soweit sie in Lymphspalten liegen, zu kurzen Fäden ausgewachsen. (Taf. III, Fig. 15.) Auch hier sind die weit vorgedrungenen Bacillen niemals phagocytirt.

Nach 24 Stunden. In dem vom Walle eingeschlossenen Gewebe liegen viele Milzbrandbacillen und zwar weniger im Centrum, als am Rande, ziemlich nahe an den Leukocyten. Die Lagerung der einzelnen Individuen ist parallel mit dem Walle, als ob sie demselben entlang gewachsen wären. - Diese Bacillen sind sãmmtlich sehr gut gefärbt. Dagegen färben sich die zwischen den Leukocyten liegenden vielfach schlecht, oft nur einzelne Körnchen darin; auch die Contouren sind nicht mehr 
regelmässig, sondern theilweise verquollen. Dieses Verhalten zeigen besonders diejenigen, die einzeln zwischen grossen Mengen von gut exhaltenen oder nahe bei zerfallenen Leukocyten liegen, während die unter denselben Verhältnissen dicht liegenden Bacillen regelmässig gefärbt sind.

\section{Pneumokokken.}

Wegen des dünnen Wachsthums auf künstlichen Nährböden konnten bei den Pneumokokkenmäusen nicht so grosse Mengen von Bakterien eingeführt werden, wie es bei anderen, z. B. den mit Milzbrand inficirten manchmal geschah. Es wurden daher Pneumokokken in manchen Schnitten gar nicht, in anderen nur in einzelnen Exemplaren nachgewiesen. Zur Beurtheilung kamen selbstverständlich nur solche Schnitte, in denen wirklich die Kokken gesehen wurden.

Die Pneumokokken, mit denen gearbeitet wurde, stammten aus zwei verschiedenen Pneumonieen; sie wurden durch mehrere Mäuse geschickt und schliesslich zur Infection der zu untersuchenden Thiere ein Mal Serum, das andere Mal Glycerinagarculturen benutzt, die beide durch directes Ausstreichen der Organe frisch gestorbener Măuse auf die betreffenden Nährböden erhalten wurden. Auf diese Weise sollte einem Virulenzverlust, der bei der Züchtung auf künstlichen Nährböden bekanntlich sehr schnell eintritt, möglichst entgegengearbeitet werden.

Aussehen nach 2 Stunden Die Pneumokokken sind ins Gewehe eingedrungen und zwar sind sie sowohl seitlich vom Schnitt in der Epidermis als auch an der Grenze zwischen Fettgewebe und Hautmuskel, bis zu dem der Schnitt geht, sichtbar. Es sind einzelne Kokken, meist aber Paare zu sehen; letztere liegen mit ihrer Lāngsaxe den Bindegewebsfasern parallel. In der Lymphdrüse sind keine Pneumokokken zu sehen.

Nach 4 Stunden. Die Kokken liegen meist in Paaren, selten einzeln oder in Häufchen; Ketten sind nicht zu sehen. Die Kokken sind theilweise über die Infectionsstelle hinausgedrungen, anscheinend ebensoweit wie vorher. Diejenigen, welche zwischen den Leukocyten liegen, sind sämmtlich frei, nicht phagocytirt. In der Lymphdrüse sind keine Kokken.

$\mathrm{Nach} 8$ Stunden. An der Infectionsstelle haben sich grosse Mengen von Leukocyten angesammelt; die dazwischen liegenden Kokken sind vielfach phagocytirt, oft auch frei. Es sind nur Diplokokken zu sehen; nur direct am Wundrande kommen auch kleine Häufchen vor. In den seichten (das Corium nicht durchdringenden Schnitten) gehen die Pneumokokken nicht über den Leukocytenwall hinaus; in den tiefen Schnitten haben sie sich in ziemlich grosser Zahl weit ins Gewebe hinein verbreitet. Auch hier liegen viele Leukocyten in ihrer Nähe, doch nicht in dichten Haufen; 
die Phagocytose ist an solchen Stellen spärlich, die meisten Kokken sind frei. In der Lymphdrüse - die übrigens durch eine breite Schicht Bindegewebe von den äussersten Kokken getrennt ist - sind keine Kokken zu sehen.

Nach 12 Stunden. Dasselbe Bild wie nach 8 Stunden.

Nach 24 Stunden. Die Pneumokokken, sämmtlich in Paaren, liegen überall im Bindegewebe verstreut, manchmal so dicht, dass man sie schon mit schwacher Vergrösserung sehen kann (Taf. II, Fig. 11 u. 12). Zwischen ihnen liegen zahlreiche Leukocyten. Ein Theil von diesen hat Pneumokokken phagocytirt, die meisten liegen in einigem Abstand von ihnen. Manchmal sieht man Leukocyten, die sehr viele Pneumokokken enthalten. Wo die Bindegewebsspalten erweitert sind, sieht man, dass die Pneumokokken nicht in den Hohlräumen, sondern an den Bindegewebsfasern liegen, so dass sich ein ganzes Netz von Pneumokokken durch das Gesichtsfeld zieht.

\section{Schweinerothlauf.}

Die Beurtheilung dieser Präparate bot stellenweise grosse Schwierigkeiten; die Bacillen sind so klein, dass einzelne Exemplare in Präparaten, die wie gewöhnlich gefärbt sind, leicht übersehen werden können, zumal da, wo viele Zellkerne liegen. Es mussten deshalb die Präparate zarter als sonst gefärbt werden; besonders gute Bilder ergab die Färbung mit Methylgrün-Eosin. Wie bei den Pneumokokken, so war es auch hier nicht möglich, grosse Mengen von Bakterien in die Wunde zu bringen, da der Agarrasen zu zart war. Die benutzten Bacillen sind seit längerer Zeit in der Bakteriensammlung des Instituts; sie tödten eine Maus nach 36 bis 48 Stunden.

Aussehen nach 4 Stunden. In der Infectionsstelle liegen die Bacillen in kleinen Häufchen; andere sind über dieselbe hinaus und weit in's Gewebe eingedrungen. Irgend welche Unterschiede in Grösse und Lagerung sind nicht zu sehen. Die Leukocyten liegen in sehr grosser Menge an der Wunde ziemlich nahe an den Bacillen; an solchen Stellen herrscht rege Phagocytose; doch sind auch viele nicht phagocytirte zwischen den Leukocyten.

Nach 8 Stunden. Tngefähr dasselbe Bild.

Nach 12 Stunden. An der Infectionsstelle sind noch dieselben Häufchen zu sehen wie vorher. Die zwischen den Leukocyten liegenden Bacillen sind grösstentheils phagocytirt; doch ist z. B. ein kleines Häufchen auf drei Seiten ron Leukocyten in geringem Abstande umgeben, und nur auf der vierten Seite wird es von diesen berührt. Im Gewebe befinden sich vielfach vereinzelte Bacillen zwisehen den zuwandernden Leukocyten; nur ganz wenige von diesen sind phagocytirt. 
Nach 24 Stunden. Von der Infectionsstelle aus ziehen sich die Bacillen in ununterbrochenem Zuge längs der Unterseite des Hautmuskels hin. In diesem Zuge liegen keine Leukocyten, dagegen an den Seiten in geringem Abstand. Direct an der Infectionsstelle sind viele Bacillen von einem der an den Ecken der Wunde oft vorkommenden Leukocytenhaufen umgeben und phagocytirt; auf dem weiteren Verlauf sind die meisten frei, nur wenige phagocytirt.

\section{Tuberkelbacillen.}

Die Färbung der Schnitte geschah jedes Mal 1. mit HämatoxylinCarbolfuchsin, 2. Anilingentiana-Hämatoxylin, 3. Carbolfuchsin-Bismarckbraun, 4. Anilingentiana-Bismarckbraun. Die besten Präparate lieferten die nach der ersten Methode behandelten Schnitte.

Zur Infection wurde eine 4 Wochen alte Serumcultur verwendet; sie stammt aus tuberculösem Sputum und wurde seit etwa einem Jahre fortgezüchtet. Für Meerschweinchen ist sie pathogen.

Ausseben nach 2 Stunden. Die Bacillen liegen theils einzeln, theils in Häufchen am Rande des Schnittes; die meisten sind gut, wenige körnig gefärbt.

Nach 4 Stunden. Die Bacillen sind auch weiter im Gewebe sichtbar; um sie herum hat sich ein grosser, ausserordentlich dichter Leukocytenhaufen gebildet; sämmtliche in diesem liegende Bacillen sind phagocytirt; meist liegen viele Tuberkelbacillen in einer Zelle. Zwischen diesen Haufen, der am Grunde der Schnittwunde liegt, und die Epidermis sind ebenfalls Tuberkelbacillen eingedrungen; diese liegen frei, theils einzeln, theils in kleinen Häufchen; auch in ihrer Nähe sind keine Leukocyten. In einigen Präparaten sind Bacillen durch den Schnitt tiefer in das Gewebe eingebracht worden; auch hier hat sich eine grosse Menge Leukocyten um sie angesammelt, dieselben haben auch die Schnittwunde ausgefüllt und die darin liegenden Bacillen phagocytirt.

Nach 8 Stunden. Dasselbe Bild. Alle eingedrungenen Bacillen sind phagocytirt.

Nach 12 Stunden. Dasselbe Bild. Irgend welche Vermehrung der Bacillen ist nicht zu erkennen.

Nach 24 Stunden. Man sieht bei dem tiefen Schnitte noch viele zuwandernde Leukocyten. Am Rande der Wunde, wo keine Leukocyten zukommen, sieht man Tuberkelbacillen einzeln oder in Häufchen liegen; im Leukocytenhaufen sind selten einzelne Bacillen und mässig viele $\mathrm{Ba}$ cillenhäufchen zu sehen. Um mehrere Bacillenhäufchen, die in einiger Entfernung von der Infectionsstelle im Gewebe liegen, haben sich polynucleäre und mononucleäre Leukocyten angesammelt; diese Häufchen sind 
leicht von Tuberkeln durch das Fehlen von epitheloiden Zellen zu unterscheiden. Auch gelingt es, dieselbe Erscheinung bei intraperitonealer Injection von schlecht verriebener Tuberkelbacillen-Reincultur hervorzurufen. Es sammeln sich auch dann um die in Häufchen zusammengebliebenen Bacillen Leukocyten an, während die einzeln liegenden Bacillen phagocytirt werden.

Nach 14 Tagen hat sich die Infectionsstelle neu überhäutet; das unter der neugebildeten Epidermis liegende Bindegewebe ist noch stark kleinzellig infiltrirt. Bei starker Vergrösserung sind darin noch sehr viele Tuberkelbacillen zu sehen, sämmtlich in einkernigen Zellen liegend.

\section{Gelbe Sarcine.}

Diese Sarcine stammte aus der Bakteriensammlung des Instituts, wo sie schon seit Jahren fortgezüchtet wird. - Zur Färbung sei bemerkt, dass sie sich nicht so gut nach Gram färbte, wie die übrigen untersuchten Bakterien; sie giebt ihren Farbstoff bei der Entfärbung schneller $a b$ und erscheint dann bei zu starker Entfärbung bei den mit Bismarckbraun nachgefärbten Schnitten in dieser. Farbe.

Aussehen nach 2 Stunden. Die Sarcinen liegen theils in der Wunde, theils sind sie schon in das Gewebe eingedrungen. Da, wo sie im Schnitte in dichten Haufen liegen, sind sie klein und liegen unregelmässig zu einander; im Gewebe sind sie grösser und liegen fast stets in Paaren oder Tetraden. An der Infectionsstelle sind schon zihlreiche Leukocyten, die viele Sarcinen phagocytirt haben.

$\mathrm{Nach} 4 \mathrm{Stunden.} \mathrm{Die} \mathrm{Sarcinen} \mathrm{liegen} \mathrm{theils} \mathrm{in} \mathrm{Paaren,} \mathrm{manche}$ in Tetraden, meist unregelmässig zu einander in Häufehen. Regelmässige Packete konnten nicht bemerkt werden. Viele sind fortgeschwemmt (Taf. II, Figg. 9 u. 10), unter diesen befinden sich sowobl kleine wie grosse. An einer Stelle sieht man, wie ein ganzer Zug in unregelmässigen Windungen genau dem Verlaufe einer Bindegewebsspalte entsprechend in das Gewebe eindringt; Leukocyten sind an dieser Stelle nicht zu sehen, da der Schnitt weit klaffi (siehe weiter unten). Andere sind sehr zahlreich seitlich in's Bindegewebe eingedrungen und dort von einem Ieukoeytenhaufen umgeben und sämmtlich phagocytirt. Im Inneren der meisten dort liegenden Leukocyten befinden sich Kokken.

Nach 8 Stunden. Die Sarcinen liegen wie vorher in Paaren, Tetraden und Häufchen; Packete kommen nicht vor.

Nach 12 Stunden. Dasselbe Bild wie vorher.

Nach 24 Stunden. Die Sarcinen bieten dasselbe Bild wie vorher; wo. sie in einiger Entfernung ron den Leukocyten liegen, sind mehr Häufchen zu sehen. In den Leukocytenhaufen, die bis dahin stets Kokken 
enthalten haben, sind nun nur noch ganz vereinzelte zu sehen; dagegen sind noch viele Kokken da vorhanden, wo sie dicht oder in einiger Entfernung von den Leukocyten an der Infectionsstelle liegen.

Die culturelle Untersuchung wurde auch hier in der gleichen Weise vorgenommen wie bei den Staphylokokken; es wurde in eine Hauttasche eine ganze Oese Cultur eingebracht. Schon nach 24 Stunden wurde vollständige Abtödtung constatirt; im Ausstrich und im Schnitt waren nur noch schlecht gefärbte, zerfallene oder verquollene Sarcinen nachweisbar, die im Schnitt sämmtlich intracellulär, im Ausstrich vielfach extracellulär lagen. Dass hier Kokken mikroskopisch noch nachweisbar waren, dürfte daher kommen, dass in die Hauttasche mehr eingeführt werden konnten als in die offene Wunde.

\section{Heubacillen.}

Die Heubacillen, mit denen gearbeitet wurde, waren auf Kartoffeln gefunden worden. Sie unterschieden sich in Nichts von den gewöhnlichen Heubacillen; auf Kartoffeln wuchsen sie mesentericus-ähnlich.

Wie bei manchen anderen Bakterien, so war es auch hier nicht leicht, grössere Mengen in die Wunde zu bringen, da die Bacillen auf Agar nur sehr dünn wuchsen.

Aussehen nach 2 Stunden. Da, wo die Bacillen dicht liegen, so wie sie eingebracht wurden, sind nur kurze Stäbchen vorhanden. Dagegen sind sie im Gewebe und an Stellen des Coagulums, wo sie mehr einzeln liegen, öfters länger, ungefähr doppelt so lang. Ziemlich viele Leukocyten sind an der Infectionsstelle zu sehen; dieselben haben theilweise Bakterien aufgenommen.

Nach 4 Stunden. Die im Gewebe liegenden Bacillen haben sämmtlich die grosse Form. Irgend welche Besonderheiten in der Lage wurden nicht bemerkt. Die Bacillen, zu denen Leukocyten kommen, sind sämmtlich phagocytirt.

Nach 8 und 12 Stunden. An der Infectionsstelle sind die Bacillen meist gut gefärbt; sie liegen einzeln oder in kleinen Häufchen zusammen. Die Häufchen liegen in einiger Entfernung von einander innerhalb des Leukocytenwalles; sie bestehen aus kleinen, gutgefärbten Bacillen. Zwischen und in den Leukocyten, die den Wall bilden, sind fast keine Bacillen zu sehen; auch weiter im Gewebe sind sie sehr spärlich vorhanden und sämmtlich phagocytirt.

Nach 24 Stunden. Am Rand der seichten Wunde liegen gut gefärbte Bacillen; im Leukocytenwall und im Gewebe sind nur sehr wenige zu sehen. 


\section{Zinnober.}

Zur Infection mit Zinnober wurde käuflicher rother fein pulverisirter Zinnober benutzt; die grössten Körnchen hatten eine Breite von $2 \mu$, die kleinsten waren bei 800 facher Vergrösserung kaum sichtbar. Die Hautstücke wurden nicht in Sublimat, sondern nur in Alkohol fixirt; die Schnitte wurden sämmtlich mit Lithioncarmin, Bismarckbraun und Hämatoxylin gefärbt. Da Zinnober in Wasser, Alkohol und Salzsäure unlöslich ist, so schien bei dieser Behandlung eine chemische Veränderung oder Lösung der in den Präparaten vorhandenen Bestandtheile ausgeschlossen; doch wurde zum Ueberfluss auch jedes Mal ein Schnitt ungefärbt und nur durch Xylol som Paraffin befreit untersucht. Trotzdem war in den Präparaten ein Theil in metallisches Quecksilber rerwandelt.

Die Beurtheilung der Schnitte bot manchmal grosse Schwierigkeiten, da viele Zinnoberkörnchen anf den Schnitten lagen. Es scheint, dass diese durch das Mikrotommesser nicht zertheilt, sondern in toto losgerissen und auf eine andere Stelle übertragen werden. Die Erkennung solcher Körnchen ist leicht, wenn sie nicht in der Schnittebene liegen; in zweifelhaften Fällen giebt ein geringes Hin- und Herdrehen des Spiegels bei künstlicher Beleuchtung sichere Entscheidung. Schwieriger ist sie dann, wenn die Körnchen in eine Lücke des Schnittes übertragen wurden etwa in eine Bindegewebsspalte oder in eine Fettzelle - und nun in gleicher Höhe liegen. Es lassen daher nur solche Zinnoberkörnchen eine sichere Beurtheilung zu, bei denen keines ron beiden der Fall ist. Besonders ist dabei der Vergleich von nahe an einander liegenden Schnittpräparaten werthvoll.

Nach 2 Stunden. In der Wunde liegen zahlreiche Zinnoberkörnchen in allen Grössen. Einige sind auch in geringer Entfernung in's Gewebe eingedrungen. Leukocyten sind nur ziemlich spärlich vorhanden.

Nach 4 Stunden. Von der Wunde, die bis in das Fettgewebe geht, sind Zinnoberkörnchen weiter in das Gewebe hinein resorbirt worden; sie bilden eine fortlaufende Linie bis zum Hautmuskel, die sich dort theilt und an seiner Ober- und Unterseite fortsetzt. Von Schnitten, die nur die Epidermis durchdringen, sind keine Zinnoberkörnchen weiter eingedrungen. An der Infectionsstelle sind viele Leukocyten, die zahlreiche. Zinnoberkörnchen aufgenommen haben.

Nach 8 Stunden. In der Umgegend der Infectionsstelle sind noch mehr Leukocyten za sehen. Dieselben haben die mehr vereinzelt liegenden kleinen Zinnoberkörnchen aufgenommen, grössere werden von mehreren umgeben; die in der Wunde in dichten Mengen liegenden sind wallartig umgeben. Viele Körnchen sind auch in das tiefere Gewebe resorbirt 
worden. Die Resorption findet besonders statt in einer entzündlich erweiterten Bindegewebsspalte, wo die Körnchen in continuirlicher Folge liegen; (Taf. I, Fig. 1) nach der Seite sind sie mehr einzeln resorbirt. Auch die resorbirten Körnchen sind theilweise phagocytirt oder von Leukocyten umgeben. Ihre Grösse geht von ganz kleinen bis zu $1.5 \mu \mathrm{im}$ Durchmesser; dabei ist nicht ausgeschlossen, dass sich nicht unter denen, die unmessbar sind, weil sie von kleineren in dichten Haufen umgeben werden, noch grössere befinden.

Nach 12 Stunden. An der Infectionsstelle derselbe Befund. Um Zinnoberkörnchen, die weiter in das Bindegewebe hinein resorbirt sind, haben sich Leukocytenhaufen angesammelt, die von solchen, welche um Bakterien liegen, nicht zu unterscheiden sind. Die Zinnoberkörnchen sind dort sämmtlich phagocytirt. - Von Wunden, die nicht einmal das Corium ganz durchsetzen, sind Zinnoberkörnchen durch das Fettgewebe und den Hautmuskel bis ziemlich tief in das Bindegewebe hinein resorbirt worden. Weitaus die meisten sind phagocytirt, nur wenige frei.

Nach 24 Stunden. Bei seichten Schnitten, bei denen die Infectionsstelle schon abgestossen wurde, indem an ihre Stelle normales Epithel getreten ist, sind im anliegenden Fettgewebe noch immer ziemlich viele mit Zinnoberkörnchen beladene Leukocyten zu sehen. Bei tiefen Schnitten, die bis in das Bindegewebe gehen, sind die grösseren Mengen wie nach 12 Stunden von einem Leukocytenmantel umgeben; ausserdem befinden sich im Bindegewebe überall zerstreut Leukocyten, die Zinnoberkörnchen aufgenommen haben. Freie Zinnoberkörnchen sind nicht zu sehen.

\section{Zusammenfassung der Resultate.}

Die in eine Wunde eingebrachten Staphylokokken wachsen dort an Grösse und theilen sich zu Paaren und Tetraden und schliesslich zu Häufchen. Dieses Resultat ist in verschiedener Beziehung bemerkenswerth.

Die erste auffallende Erscheinung ist die Vergrösserung. Dass die kleinen Formen und nicht die grossen für die eingebrachten zu halten sind, ist klar. Zwar wurde kein Vergleich mit einem Ausstrichpräparat der Reincultur angestellt, da die Präparation der beiden eine zu verschiedene ist: bei den einen das einfache Antrocknen, bei den anderen Tage lange Behandlung mit Alkohol, dann mit Alkalien und Säuren. Es konnte daher ein Vergleich solcher Präparate keinen unanfechtbaren Beweis liefern. Dagegen ist als solcher zunächst das Zahlenverhältniss der kleinen und grossen Kokken anzusehen: Anfangs überwiegen die kleinen weit, später treten sie ganz zurück. Auch der Umstand, dass die kleinen 
Kokken sich hauptsächlich und später nur in den Haufen vorfiuden, spricht dafür: dort ist Mangel an Nährstoffen und vor Allem gegenseitige Behinderung durch Stoffwechselproducte vorhanden, die bei den einzeln liegenden wegfällt. Ferner könnte man die grossen Kokken für gequollene Degenerationsformen halten. Dies ist aber nicht statthaft, da sie sich einerseits sehr gut färben, und da andererseits gerade sie es sind, die sich vermehren. - Ausserdem ist die Grösse der Kolken im Präparate auch in gewissem Grade von der Färbung abhängig: Bei sehr lange dauernder Entfärbung sehen die Kokken viel kleiner aus als bei richtiger Entfärbung. Doch müssten, abgesehen davon, dass die Technik möglichst sorgfältig gehandhabt wurde, dann gerade die einzeln liegenden Kokken kleiner erscheinen, da sie sich viel eher entfärben als die in Haufen liegenden. - Ueberhaupt darf es nicht auffallen, dass Bakterien gleicher Art auf verschiedenen Nährböden verschiedene Grössen zeigen: man vergleiche nur auf Agar und Gelatine gewachsene Typhusbacillen mit einander; die letzteren haben mindestens die doppelte Breite und eine relativ noch viel grössere Länge als die ersteren.

Als zweites hervorstechendes Moment sind die Theilungen zu bezeichnen. Dieselben geschehen stets in zwei auf einander senkrechten Richtungen, ein Verhalten, das man auch stets in Bouillonculturen beobachtet, wo sich dann die neu entstandenen Paare gegen einander. verschieben und ein Parallelogramm bilden. Zum Beweise, dass die erwähnte Stellung wirklich durch Theilung zu Stande kommt, wurde folgender Versuch angestellt: Eine Agarplatte, auf der sich eine 24 stündige Staphylokokkencultur befand, wurde umgedreht und auf die Unterseite des Deckels, die jetzt den Boden bildete, Chloroform gegossen. Nachdem die Platte 6 Stunden so liegen geblieben war, wurde sie mit einem neuen Deckel versehen in den Brütschrank gestellt; der Deckel wurde schief aufgesetzt, so dass das Chloroform, das gasförmig in die Kokkenmasse gelangt war, entweichen konnte. Controlproben auf Bouillon ergaben, dass die Staphylokokken abgetödtet waren. Mit dieser Cultur wurden Mäuse in der gewöhnlichen Weise inficirt und die Infectionsstellen im Schnitte untersucht.

A ussehen nach 4 Stunden. Im Präparate sind nur kleine Kokken zu sehen; weder Paare noch Tetraden sind vorhanden. Phagocytose.

Nach 8 Stunden. Auch jetzt sind keine grossen Kokken und keine Theilungsformen vorhanden.

Besonders interessant ist die Thatsache der Vermehrung dadurch, dass sie in den Gewebssäften der gegen die Staphylokokken immunen Maus stattfindet. Es beweist dies, dass die Immunität der Maus weder darauf beruht, dass die Kokken nicht im Stande sind, dort zu wachsen, weil sie keinen günstigen Nährboden vorfinden, noch darauf, dass sie 
durch im Plasma circulirende, präformirte Stoffe abgetödtet werden. Denn in diesem Falle müssten diese Stoffe gerade die am weitesten vorgedrungenen Kokken treffen; und, da sie durch die Cireulation ständig neu herbeigeschafft werden, diese abtödten; höchstens die im dichten Haufen liegenden könnten zur Vermehrung gelangen: gerade das Umgekehrte ist aber der Fall.

Die Beziehungen zwischen den Kokken und den Leukocyten sind folgende: Die Leukocyten dringen nicht immer bis zu den Leukocyten vor. Es bleibt zwischen ihnen ein geringer Abstand, erstens, wenn die Kokken - einzelne oder viele - am äussersten Rande der Wunde liegen; zweitens, wenn sehr dichte Kokkenhaufen weiter innen liegen. Diejenigen Kokken, die einzeln oder in kleinen Häufchen weiter innen liegen, sind sie nach 4 Stunden meist, nach 8 bis 12 Stunden sämmtlich phagocytirt; gerade die am weitesten eingedrungenen werden zuerst aufgenommen, was leicht begreiflich ist, da ihnen zuerst die Leukocyten entgegen kommen.

Die aufgenommenen Kokken gehen in den Leukocyten allmählich zu Grunde. Für eine vorhergehende Vermehrung ist kein Anhaltspunkt vorhanden; die in den Leukocyten liegenden Tetraden und Häufchen können selbstverständlich nicht als Beweis dafür angesehen werden, da sie wahrscheinlicher als solche phagocytirt wurden. - Das Zugrundegehen geschieht nicht zwischen, sondern in den Leukocyten; nach 14 Tagen waren mikroskopisch, nach 3 Wochen culturell keine Kokken mehr nachweisbar. Da Staphylokokken innerhalb dieser Zeit weder auf Nährböden - durch Stoffwechselproducte - noch ausgetrocknet - durch Nahrungsmangel zu Grunde zu gehen pflegen, so muss ihr Untergang der Einwirkung der Leukocyten zugeschrieben werden.

Die Milzbrandbacillen dringen wie die Staphylokokken in die Wunde ein und vermehren sich darin und in ihrer Umgebung. Dabei zeigen auch sie verschiedene Formen je nach ihrer Lage. Diese Formen sind wahrscheinlich ebenso wie bei den Staphylokokken Vermehrungsformen, denn da, wo bei diesen Paare und Tetraden liegen, liegen bei den Milzbrandbacillen kurze Formen, oft zu zweien. Man wird daher annehmen müssen, dass sich eingebrachte kurze Fäden zuerst in einzelne Glieder theilen und diese sich dann erst vermehren.

Die Ausbreitung im Gewebe geschieht bei den Milzbrandbacillen Anfangs ebenso schnell, dann schneller als bei den Staphylokokken; die Bacillen dringen sowohl seitlich bis in die Epidermis als auch nach unten vor. Dieses Vordringen ist wesentlich davon abhängig, in welche Tiefe die Milzbrandbacillen eingebracht wurden: war der Schnitt seicht, durch- 
trennte er also nur die Epidermis, das Corium und einen Theil des Fettgewebes, so bildete sich ein Wall von Leukocyten um den Bacillenherd herum, manchmal noch ehe die Bacillen in die Gewebe eindringen konnten.

Was die Beziehungen zwischen den Milzbrandbacillen und den Leukocyten betrifft, so ist folgendes zu bemerken: In dem Leukocytenwall, der die Wunde umgiebt, liegen Bacillen und Leukocyten unter einander. Nur wenige Bacillen sind phagocytirt - sie liegen dann, oft zusammengekrümmt, neben dem Kerne. Vielfach dagegen liegen die Leukocyten mit dem Protoplasma den Bacillen dicht an; oft liegt aber auch das Protoplasma in einiger Entfernung von den nächsten Milzbrandbacillen. Dasselbe Verhältniss ist auch dann zu bemerken, wenn weiter vorgedrungene Milzbrandbacillen von einem Leukocytenhäufchen sichel- oder ringförmig umgeben werden. Dagegen sind die einzeln in's Gewebe vorgedrungenen Milzbrandbacillen, im Gegensatz zu den Staphylokokken, fast niemals phagocytirt, und wenn sie in grösseren Haufen im Bindegewebe liegen, so sind nicht einmal auf sie zuwandernde Leukocyten zu sehen.

Bis zur 12. Stunde einschliesslich ist ausser der gekrümmten Form der aufgenommenen Bacillen nichts Auffallendes an ihrer Gestalt zu sehen; nach 24 Stunden dagegen erscheinen die Bacillen, die in oder zwischen dicht stehenden Leukocyten oder nahe bei zerfallenen liegen, schlecht färbbar und in ihrer Form verquollen, während die übrigen, auch die im Coagulum befindlichen, gut gefärbt und regelmässig gestaltet sind. Dieser Zerfall darf wohl als Abtödtung von aussen her angesehen werden. Allerdings kommen oft unter den günstigsten Verhältnissen ähnliche Formen ror: so findet man stets in Klatschpräparaten einer 8 Stunden alten Agarcultur einige ganz schlecht gefärbte Bacillen, während die übrigen Glieder der Kette gut gefärbt sind. Wenn aber, wie es hier der Fall ist, die zwischen den Leukocyten liegenden Bacillen schlecht, die weit ron ihnen entfernten gut sind, so darf man wohl an Ursache und Wirkung denken.

Die Pneumokokken, von denen ein Paar ungefähr die Länge und Breite eines Milzbrandbacillus hat, dringen wie dieser in die Gewebe ein. Vermehrungsformen konnten bei ihnen nicht nachgewiesen werden, wenn man nicht die sehr selten und nur am Wundrande vorkommenden Tetraden und Häufchen dafür halten will. Es ist wohl anzunehmen, dass sich die Paare gleich nach ihrer weiteren Theilung trennen und von einander fortgeschwemmt werden. Die Ausbreitung scheint nach 8 Stunden etwas langsamer als beim Milzbrand erfolgt zu sein; doch beruht dies möglicher Weise darauf, dass weniger eingeführt wurden. - Betreffs der Ansammlung der Leukocyten und der Beziehungen derselben zu den Bacillen 
liegen die Verhältnisse wie beim Milzbrand, nur dass vielleicht bei den Pneumokokken die Ansammlung eine noch stärkere ist. Degenerationsformen wurden nicht bemerkt.

An den Schweinerothlaufbacillen sind Formen, die auf Theilung bezogen werden könnten, nicht zu sehen. Das Eindringen in das Gewebe scheint hier schneller vor sich zu gehen als bei den bisher besprochenen Bakterien, was mit ihrer geringeren Grösse zusammenhängen mag. Die Leukocytenansammlung an der Infectionsstelle ist eine auffallend starke. Die Phagocytose ist stärker als bei Milzbrand, doch wurden nicht alle an der Infectionsstelle liegenden Bacillen aufgenommen; die weiter in's Gewebe eingedrungenen sind zum grössten Theile frei. Ueber abgetödtete Formen konnte keine Beobachtung gemacht werden.

Auffallend ist bei dem ganzen Verlaufe die geringe Phagocytose, da sie bekanntlich in den an Schweinerothlauf gestorbenen Thieren in sehr hohem Maasse vorhanden ist. Es muss daher angenommen werden, dass die Leukocyten im Verlaufe der Krankheit die Fähigkeit erlangen, die Bacillen aufzunehmen. Eine solche Immunisirung im Verlaufe einer tödtlichen Krankheit hat ja nach den Untersuchungen Radziewsky's nichts Unwahrscheinliches mehr.

Bei den Tuberkelbacillen ist ebenfalls keine Vermehrung nachweisbar. Die Phagocytose ist auch hier sehr stark, so dass nach kurzer Zeit sämmtliche Bacillen aufgenommen oder umringt sind; eine Zerstörung hat aber auch nach 14 Tagen noch nicht stattgefunden.

Bei der gelben Sarcine liegen ähnliche Verhältnisse wie bei den Staphylokokken vor. Auch hier sind kleine und grosse Formen zu sehen, ebenso einzeln liegende, Paare, Tetraden und Häufchen, während Packete nicht beobachtet wurden. Dürfen nun diese Formen als Vermehrungsformen gedeutet werden? Die Paare und Tetraden sprechen dafür, das Fehlen ron Packeten dagegen. Immerhin ist es leicht möglich, dass durch das Strömen der Gewebssäfte eine Trennung und Verschiebung der Kokken gleich nach ihrer Theilung stattfindet, so dass an Stelle der Packete die Häufchen treten; hierfür spricht vor Allem die Zunahme der Häufchen im Gewebe bei längerer Dauer der Infection. Auch werden bekanntlich nicht auf allen Nährböden Packete gebildet. Es würde also dann auch hier wieder der Fall vorliegen, dass sich Kokken in einem gegen sie rollständig immunen Thiere rermehren können; es fehlt ihnen also darin weder an Nahrungsstoffen, noch sind im lebenden circulirenden Plasma Substanzen gelöst, die die Sarcinen abtödten. Das erstere ist ja auch deshalb unwahrscheinlich, weil die Sarcinen auf Blutserum bei $37^{\circ}$ unter kräftiger Verflüssigung des Nährbodens wachsen. 
BeItRÄGE ZUR LeHRE VON DER NATÜRLICHEN IMIMUNITÄT. I. 31

Die eingedrungenen Sarcinen werden ron den zukommenden Leukocyten sehr schnell phagocytirt; fast alle an einer solchen Stelle liegenden Leukocyten haben Sarcinen aufgenommen. Nach 24 Stunden sieht man in den im Gewebe liegenden Leukocytenhaufen, die nach kürzerer Zeit nie ohne Bakterien sind, keine Sarcinen; da die direct an der Infectionsstelle liegenden, auch wenn sie einzeln liegen, noch gut gefärbt sind, so ist nicht anzunehmen, dass dies auf einer starken Entfärbung beruht, sondern es dürfte dies wohl als Beweis dafür angesehen werden, dass die Sarcinen im Inneren der Leukocyten abgetödtet wurden, was auch der Culturversuch beweist.

Auch die Heubacillen zeigen gewisse Formveränderungen, die aber nicht constant sind. Nach 2 und 4 Stunden wurden längere Bacillen beobachtet; nach 12 und 24 Stunden waren diese nicht mehr vorbanden. Dagegen zeigten sich nach 8 und 12 Stunden an der Infectionsstelle, aber noch innerhalb des Leukocytenwalles in einiger Entfernung von diesem kleine Häufchen, die in geringer Entfernung von einander lagen, während einzelne Bacillen nur spärlich vorhanden sind. Nach der Lage der Bacillen und Häufchen zu einander, besonders da die Häufchen nicht mit einzelnen Bacillen in Verbindung stehen, sondern in sich abgeschlossen sind, ist es möglich, dass es sich auch hier um Vermehrungsformen handelt. - Im Gewebe geht die Phagocytose sehr rasch vor sich; nach 24 Stunden sind zwischen den Leukocyten fast keine Bacillen mehr zu sehen; auch hier dürfte es sich um Abtödtung handeln.

Das Eindringen des Zinnobers geschieht auf dem gleichen Wege und auch sonst in ganz ähnlicher Weise wie das der Barterien. Die Menge der resorbirten Körnchen scheint in den Präparaten grösser zu sein als die der resorbirten Bakterien, die nach 4 und 8 Stunden' niemals in so ununterbrochenem Zuge von der Wunde in die Gewebe eindrangen; doch kann dies wohl mit der grossen Menge des eingeführten Zinnobers erklärt werden. - Auch im weiteren Verlaufe zeigt sich kein bedeutender Unterschied von den Bakterien; wie bei diesen sammeln sich um viele einzeln in Gewebe liegende Leukocytenhaufen an und die dort liegenden Körnchen werden phagocytirt. Die Phagocytose der ganz vereinzelt liegenden dagegen ist eine langsame; nach 12 Stunden sind noch nicht alle aufgenommen, dagegen nach 24 Stunden. 


\section{Betrachtung nach der Tiefe der Wunden.}

Aus den bisher angeführten Thatsachen sieht man, dass die Verhältnisse bei Infectionen ziemlich stark modificirt werden können. Es kommen in Betracht einerseits die Art und Zahl der Mikroorganismen, andererseits die Tiefe und Breite des Schnittes.

Eine Klarheit über die mitgetheilten Resultate lässt sich erst dann erreichen, wenn dieselben nochmals nach anderen Gesichtspunkten mit einander verglichen werden. Als solche Gesichtspunkte wurde die Gestalt des Schnittes gewählt und die Schnitte nach Tiefe und Breite folgendermaassen eingetheilt:

1. Seichte schmale Schnitte, das Corium nicht durchdringend; die Wundränder liegen meist zusammen oder stehen wenig aus einander.

2. Seichte, breite Schnitte, das Corium nicht durchdringend, meist nur die Hornschicht und die obersten Epidermiszellen wegnehmend. Die Schnitte machen den Eindruck, als ob die oberste Fläche tangential abgeschnitten oder abgekratzt wäre.

3. Mitteltiefe Schnitte, die das Corium durchdringen aber nicht den Hautmuskel erreichen, sondern noch im Fettgewebe aufhören.

4. Tiefe, schmale oder mittelbreite Schnitte. Die Schnitte gehen bis auf den Hautmuskel, durchdringen denselben aber nicht, sondern endigen dort, ohne sich zu verbreitern. Im Verlaufe stehen die Wundränder nur wenig oder gar nicht von einander ab.

5. Tiefe breite Schnitte. Die Schnitte berühren den Hautmuskel; die Wundränder sind im ganzen Verlauf aus einander gezogen, ebenso am unteren Ende, so dass der Hautmuskel eine Strecke weit bloss liegt. Manchmal sind auch in den dadurch entstandenen Ecken Fettgewebe und Hautmuskel aus einander gezogen. Die Wunde ist oft theilweise oder ganz mit Blutcoagulum ausgefüllt.

6. Breite, sehr tiefe Schnitte. Der Hautmuskel ist eben durchschnitten.

7. Schmale Schnitte ins Bindegewebe. Die Schnitte gehen in das unter dem Hautmuskel liegende Bindegewebe hinein; die Wundränder sind mit einander verklebt.

8. Breite Schnitte ins Bindegewebe. Dieselbe Tiefe; klaffend.

Die Betrachtung der Schnitte 2 Stunden nach der Infection ergiebt keine Besonderheiten von Seite des Organismus; speciell befinden sich bei: allen nur wenige Leukocyten in der Nähe der Wunde. Charakteristische Erscheinungen treten erst nach 4 Stunden auf. 


\section{Seichte, schmale Schnitte.}

Bei den Schnitten wurde anfangs besonders darauf geachtet, ob die Lage zu den Falten der Haut eine Rolle spiele, speciell ob Wunden, die auf der Erhebung einer Hautfalte liegen, ein anderes Aussehen darböten als solche in der Tiefe einer Falte. Doch ist ein solcher Unterschied höchstens insofern vorhanden, als bei letzteren die Wundränder stets mit einander verklebt waren, während sie bei letzteren öfters auseinander standen.

Aussehen nach 4 Stunden. In der Gegend der Schnittwunden, gleichgültig, ob sie inficirt sind oder nicht und mit was für Bakterien, sind zahlreiche Leukocyten zu sehen. Dieselben dringen in den Schnitten, die in einer Hautfalte liegen, bis zum Wundrande vor; doch stehen sie manchmal an demselben nicht so dicht wie in geringer Entfernung davon. Am auffallendsten war dies bei Pneumokokken. Auch bei Schnitten, die auf einer Erhebung der Haut liegen, sieht man die Leukocyten am Wundrande dicht stehen, falls die Wunde geschlossen ist; öfter dagegen stehen sie auch dann in einiger Entfernung, und stets ist dies der Fall, wenn die Wundränder nicht mit einander verklebt sind, sondern in einiger Entfernung von einander stehen. - Gelangen die Leukocyten nicht bis zum Wundrande, so bildet sich ein. Wall, der ziemlich dicht ist; (Taf. I, Fig. 2), die Dichte und Breite zeigt bei den verschiedenen Bakterien reinen Unterschied, sondern sie ist nur verschieden nach der Dauer der Infection und der Tiefe des Schnittes. Innerhalb des Walles ercheint das Gewebe ziemlich kernarm. Der Wall erscheint am dichtesten in der Mitte; nach aussen ist die Begrenzung unscharf und man sieht auch noch in einiger Entfernung zuwandernde Leukocyten. Nach innen ist der Wall ziemlich scharf begrenzt und hält sich überall in ungefähr gleicher Entfernung von dem Wundrande; nur an Stellen, wo die Bakterien nahe liegen, dringen die Leukocyten bis an den Wundrand zu ihnen vor. Dieses Verhalten wurde sowohl bei nicht pathogenen Bakterien, als auch bei Milzbrandbacillen in mässiger Menge beobachtet.

Der Zug der Leukocyten lässt sich genau verfolgen. Sehr viele von ihnen kommen im Corium von beiden Seiten der Wunde heran; ein anderer Theil, besonders, wenn der Schnitt fast das ganze Corium durchsetzte, von unten, und zwar grösstentheils aus dem Hautmuskel, mit dem sie durch die oben erwähnte Entzündungsbrücke verbunden sind, und aus den auf dem Wege liegenden Gefässen. - Geht der Schnitt schräg in das Corium, so finden sich an seinem unteren Ende die meisten Leukocyten; an der Ecke, an der die Haut im spitzen Winkel eingeschnitten ist dagegen nur sehr wenige und in weitem Abstand. 
Aussehen nach 8 Stunden. Auch jetzt ist zwischen inficirten und nicht inficirten Schnitten in der Zahl der Leukocyten kein Unterschied. Wie nach 4 Stunden ist bei einigen die ganze Umgebung der Wunde bis zu den mit einander verklebten Rändern mit Leukocyten angefüllt, in anderen ist ein Wall vorhanden, der von den Wundrändern einen ebenso grossen Abstand hält wie nach 4 Stunden. Im innersten Theil des Walles (gegen die Wunde zu) befinden sich zerfallene 'Leukocyten. Die Dichte des Walles ist gewachsen und auch in der Umgegend sind viele zuwandernde Leukocyten $z \mathbf{u}$ sehen. Ist in der Schnittwunde ein Blutcoagulum vorhanden, so ist es manchmal frei von Leulocyten, manchmal aber auch von ihnen dicht vollgepfropft. Unter den letzteren Coagulis befinden sich solche, die anscheinend an der Haut herausgedrückt wurden und nur noch in Form eines Keiles mit ihrem unteren Ende in derselben sitzen.

Nach 12 Stunden. Im Ganzen ist das Aussehen der Schnitte dasselbe wie nach 8 Stunden; nur befinden sich melr Leukocyten an der Infectionsstelle. Auch die Zuwanderung hat noch nicht nachgelassen. Dagegen ist der Wall oft an der der Wunde abgewendeten Seite schärfer umgrenzt, indem sich die Bindegewebsfasern um den Leukocytenhaufen herumziehen. Es scheint, dass die Leukocyten durch dieselben hindurchgewandert sind und sie dabei zurückgedrängt haben, so dass eine $\mathrm{Ab}$ kapselung der Wunde entstanden ist. - An manchen Schnitten lässt sich constatiren, dass die Epidermis zungenförmig zwischen Leukocyten und gesundes Gewebe hereinzuwachsen beginnt.

Die Entzündung im Fettgewebe dauert fort und es wandern auch auf diesem Wege zahlreiche Leukocyten zu; ebenso treten sie aus den dort liegenden Gefässen zahlreich aus.

Nach 24 Stunden. Das Áussehen des Leukocytenwalles gegen die Wunde $z u$ ist das gleiche; nach unten $z u$ ist er scharf abgegrenzt und hat sich in den meisten Fällen röllig von seiner Unterlage losgelöst. Diese Demarcation kann einmal dadurch geschehen, dass sich die Epidermis vollständig unter ihm durchgeschoben hat (Taf. I, Fig. 5); wo aber das Wachsthum derselben noch nicht so weit fortgeschritten ist, ist sie dadurch eingetreten, dass die erwähnte Abtrennung durch die Bindegewebsfasern sich nun vollständig vollzogen hat. - Die demarkirte Partie hängt oft noch an der Seite mit der Hornschicht, oder durch ein durchgewachsenes Haar mit ihrer Unterlage zusammen. - Zuwandernde Leukocyten sind auf dem vorhin bezeichneten Wege noch immer in unverminderter Menge zu sehen; auch die Entzündung im Fettgewebe ist noch vorhanden. 
Die in der Wunde liegenden Bakterien haben 7.war vielfach an Zahl zugenommen, doch sind sie niemals bis zu dem Walle vorgedrungen, sondern es bleibt stets ein Zwischenraum.

\section{Seichte, breite schnitte.}

Aussehen nach 4 Stunden. Um die Wunde haben sich Leukocyten angesammelt, die nie bis zu der blossgelegten Oberfläche vordringen, sondern immer in einiger Entfernung davon bleiben und hier einen Wall bilden. Die Entfernung von der Oberfläche ist im Allgemeinen grösser als bei der vorigen Schnittart; der Wall ist bedeutend dünner und ofters nur unten, nicht an der Seite vorhanden. Die Zahl der Leukocyten im Ganzen ist geringer als vorhin; und zwar ist dies nicht nur dadurch bedingt, dass die Leukocyten sich auf eine bedeutend grössere Fläche zu vertheilen haben, sondern es sind auch absolut weniger vorhanden. Nur wo ausser der durch „Abkratzen" entstandenen Wunde noch eine zweite von der vorhin beschriebenen Art vorhanden ist, ist ein dichterer Wall zu sehen. - Auch bei den seichten, breiten Schnitten kommen die Leukocyten meist durch das entzündete Fettgewebe.

Nach 8 Stunden. Mehr Leukocyten als vorher, aber immer noch weniger als bei den 8 stündigen schmalen Schnitten: der Wall ist weniger breit und die Leukocyten stehen weniger dicht. Der Wall ist noch ebenso weit von der Wunde entfernt wie nach 4 Stunden, etwas weiter als bei schmalen Schnitten. Auch die beiden Seiten der Wunde sind jetzt davon umzogen.

Nach 12 Stunden. Der Wall ișt dichter und breiter geworden; sonst dasselbe Bild.

Nach 24 Stunden. Die Unterschiede zwischen breiten und schmalen Schnitten sind verschwunden; die Schnitte sind sämmtlich demarkirt.

\section{Mitteltiefe Schnitte.}

Die Wunden gehen durch das Corium und sind an der Seite und unten vom Fettgewebe umgeben.

Aussehen nach 4 Stundeu. Um die Wunde herum liegen viele Leukocyten; doch bilden dieselben nur in der Epidermis und im Corium einen dichten, gleichmässigen Wall. Im Fettgewebe schien derselbe beim ersten Anblick dünn und unregelmässig zu sein, als ob der Schnitt zerfetzt wäre. Bei näherer Betrachtung zeigt sich, dass die Leukocyten überall da vorhanden sind, wo sie Platz finden, nämlich zwischen den Fettzellen, während diese grosse Lücken darstellen. Was der Wall dadurch an Dichte gegenüber seichten, schmalen Schnitten verliert, ist er diesen an Breite überlegen. 
Kleben die Wundränder direct zusammen, so gehen die Leukocyten oft nicht bis zu ihnen; sind sie durch ein Coagulum getrennt, so ist dies nicht von Leukocyten angefüllt.

Die entzündliche Erweiterung der Bindegewebsspalten um die Wunde ist ziemlich stark, am stärksten unten gegen den Hautmuskel zu, mit dem die Wunde durch eine breite Entzündungsbrücke rerbunden ist. Diese kann so breit sein, dass sie die Wunde ron unten ganz umfasst und den Anschein giebt, als ob die Leukocyten dort nicht im Fettgewebe lägen. - Die im Fettgewebe liegenden Leukocyten kommen meist von unten und zwar zum grossen Theil von der oberen und unteren Seite des Hautmuskels diesem entlang ziehend und, in letzterem Falle, an einer Stelle durch die aus einander gewichenen Muskelfasern durchwandernd.

Nach 8 Stunden. Das Aussehen der Schnitte ist im Ganzen wie nach 4 Stunden, nur befinden sich mehr Leukocyten in ihrer Umgebung. (Taf. I, Fig. 6). Geht der Schnitt in sehr spitzem Winkel in die Haut, so finden sich hauptsächlich an seinem unteren Ende Lenkocyten, viel weniger an der der Oberhaut zugewendeten Längsseite. In einem der Milzbranddurchschnitte ist jenseits des Hautmuskels noch ein zweiter Wall zu sehen (Taf. II, Fig. 7), der auf folgende Weise entsteht: In der Wunde selbst liegen viele Bacillen; von hier aus haben sie sich nach unten verbreitet und befinden sich sowobl zwischen den Fasern des Hautmuskels als auch etwas weiter in dem direct darunter liegenden Bindegewebe. - Die Leukocyten sind nun so vertheilt, dass zunächst ein dichter Wall um die Wunde selbst herumgeht, der übrigens, da die Entzündung im Fettgewebe stärker ist, massiger erscheint als bei anderen Schnitten. Von hier aus ziehen sich Leukocyten in dichter Menge zu dem Hautmuskel und durch diese hindurch genau auf dem Wege, den die Milzbrandbacillen genommen haben und umgeben diejenigen, die schon über den Hautmuskel hinausgedrungen sind, auch von unten, so dass ein zweiter Wall entsteht. Auch zwischen den Milzbrandbacillen liegen dort Leukocyten, wobei allerdings eine Entscheidung nicht möglich ist, ob diesèlben nicht schon vor den Milzbrandbacillen am Platze waren. In der Wunde einzeln liegende Bacillen sind von Leukocyten dicht umgeben und theilweise phagocytirt, während ein dichtes Häufchen allseitig in geringem Abstande umgeben ist.

Nach 12 Stunden. Ein dichter, breiter Wall zieht sich um die Wunde herum in geringem Abstande, wie vorher von Fettzellen unterbrochen. Die Leukocyten haben sich auf einen bestimmten Abstand concentrirt; es scheinen weniger zuzuwandern. Die Entzündung in der Umgebung besteht noch. Das Gewebe scheint im Wall, besonders an dessen 
BEITRÄGE ZUR LEHRE VON DER NATÜRLICHEN IMMUNITÄT. I. 37

von der Wunde abgewendeten Seite, sehr viel lockerer zu sein und leichter zu reissen. .

Nach 24 Stunden. Die Menge der Leukocyten hat gegen 12 Stunden nicht bedeutend zugenommen, doch sieht man immer noch zuwandernde Leukocyten; auch die Entzündung besteht noch fort. Von der Seite her schiebt sich das Epithel unter den Leukocytenwall; doch hat ein vollständiges Umwachsen noch nirgends stattgefunden, nur einmal ist das Epithel auf der einen Seite bis auf den Grund der Wunde vorgedrungen.

Ferner zeigen sich hier Unterschiede zwischen den mit pathogenen und den mit nicht pathogenen Bakterien inficirten Wunden. - Bei den Staphylokokkenwunden liegen im Zuwanderungsbezirk der Leukocyten mässig viele Staphylokokken, die sämmtlich phagocytirt sind. Die Wunde ist mit Leukocyten ziemlich dicht ausgefüllt; die darin einzeln oder in kleinen Häufchen liegenden Kokken sind sämmtlich phagocytirt; dagegen liegt am unteren Ende einer Wunde in dem mässig dichten Leukocytenbaufen ein dichter Kolikenhaufen, der in geringem Abstand ron einem besonders dichten Leukocytenring umgeben ist.

Die Milzbrandbacillen sind nicht über die Wunde hinausgewachsen. Auch in der Wunde findet man nicht viele; ein Theil von ihnen ist, extracellulär zwischen den Leukocyten liegend, zerfallen.

Bei einem Schweinerothlaufschnitt war eine ähnliche Erscheinung wie vorher der doppelte Wall zu constatiren. Die Leukocyten umgeben hier auffallend dicht die Infectionsstelle. Von hier zieht ein gleichfalls sehr dichter Leukocytenhaufen durch den Hautmuskel in das Bindegewebe hinein in derselben Breite wie der Leukocytenwall; um ihn legen sich Bindegewebszüge herum.

\section{Tiefe, mittelbreite und schmale schnitte.}

Die Schnitte gehen bis auf den Hautmuskel, dort spitz, nicht breit endigend; die Wundränder sind theilweise in ihrer ganzen Länge mit einander verklebt, theilweise klaffen die Sehnitte in der Art, dass sie oben bedeutend breiter als unten sind.

A ussehen nach 4 Stunden. Am Schnitt sind auf beiden Seiten zahlreiche Leukocyten zu sehen. Wo die Schnittränder mit einander verklebt sind, haben sie sich in grosser Menge um die dort liegenden Bakterien angesammelt; sie sind über die Wundränder hinaus gewandert und umgeben nun die zwischen ibnen liegenden Bakterien, in dem sie dabei einen dichten, mässig breiten Haufen bilden, dessen Länge so weit reicht, als der Schnitt zusammengeklebt ist. Wo die Schnittränder nicht mit einander verklebt sind, stehen sie in einigem Abstande von 
diesen. Die Zuwanderung zu dem in der Epidermis liegenden Theile des Walles geschieht in dieser; zu dem im Fettgewebe liegenden Theile theils quer durch dieses von den darunter liegenden Gefässen aus, zum grössten Theil von unten durch den Hautmuskel, dessen Fasern dabei aus einander gedrängt sind. Dorthin gelangen sie nur zum allergeringsten Theile quer durch das Bindegewebe, weitaus die meisten wandern an der unteren Seite des Hautmuskels diesem entlang. - Im Allgemeinen scheint es, als ob in den inficirten Schnitten etwas mehr Leukocyten zu sehen wären als in den nicht inficirten. - Geht der Schnitt schräg durch die Haut, so findet sich eine anffallend grosse Menge von Lenkocyten an dem Schnittrand, der den einen Schenkel des stumpfen Winkels bildet; am gegenüberliegenden Schnittrande befinden sich gar keine Leukocyten, sondern dieser keilförmig abgetrennte Theil der Haut ist von einem Leukocytenwall abgetrennt, dessen Lage einer ungefähr senkrechten Linie auf das untere Ende der Wunde entspricht. - Auch der am unteren Ende des Schnittes liegende Leukocytenhaufen kann sich nach unten längs des Hautmuskels fortsetzen, soweit Bakterien vorgedrungen sind.

Nach 8 und -12 Stunden. Die Zahl der Leukncyten hat sich vermehrt; sonst ist keine wesentliche Veränderung eingetreten.

Nach 24 Stunden. Die Demarkation hat begonnen, ist aber noch nirgends beendet; da, wo sie am weitesten fortgeschritten ist, ist das Epithel an einer Seite bis zum Hautmuskel herabgewachsen.

\section{Breite, tiefe Schnitte.}

Wie erwähnt, klaffen die meisten, bis auf den Hautmuskel reichenden Schnitte weit, so dass die Schnittwunde im Durchschnitt in Gestalt eines Viereckes erscheint, dessen eine Seite durch den Hautmuskel gebildet wird.

Aussehen nach 4 Stunden. Die Leukocyten stehen in Epidermis, Corium und Fettgewebe in gleicher Anordnung und Zahl wie in den eben besprochenen Schnitten; man kann dabei auch hier beobachten, dass sie aus den Gefässen aus der der Wunde zugekehrten Seite austreten. Die Zuwanderung zu der untersten Partie der Wunde geschieht nicht aus dem Bindegewebe, sondern von der Seite her dem Hautmuskel entlang. Die weitere Anordnung richtet sich darmach, ob der Zwischenraum zwischen den drei Wundflächen durch ein Blutcoagulum ausgefüllt ist oder nicht. Im ersteren Falle befindet sich der Leukocytenwall direct am Rande der Wunde; vereinzelte Leukocyten sind auch im Coagulum zu sehen. Ist die Schnittwunde nicht von einem Coagulum ausgefüllt, so geht der Leukocytenwall nicht bis zum Rande, sondern zieht sich in einiger Entfernung um die Wunde herum: also von der Epidermis durch das Fettgewebe, den Hautmuskel senkrecht durchbrechend, dann direct unter 
BeIträge ZUR ILEHRE VON DER NATÜRLICHEN IMMUNITÄT. I. 39

diesem bis zur anderen Seite, um dort ebenso zu verlaufen (Taf. I, Fig. 4). Meist sind die Ecken nicht spitz, sondern rund und von der Oberfläche etwas weiter entfernt als die Seiten. Die Entzündung im Fettgewebe ist dabei nur dort vorhanden, wo der Wall selbst ist.

Eine Ausnahme von dem beschriebenen Typus liegt dort vor, wo sehr dichte Bakterienhaufen dem Wundrande entlang liegen; dann gehen die Leukocyten nicht bis zum Wundrande, auch wenn die Wunde mit einem Coagulum ausgefüllt ist, sondern es bleibt ein Abstand zwischen ihnen und den Bakterienhaufen (Taf. III, Fig. 13).

Nach 8 Stunden. Die Zahl der Leukocyten hat sich bedeutend vermehrt; die Lage ist ungefähr dieselbe geblieben. Sie stehen auch jetzt noch am Rande der Wunde am Coagulum, bezw. wenn ein solches nicht vorhanden ist, in einigem Abstand von der Wunde. Auch jetzt sind keine Leukocyten zu sehen, die durch das Bindegewebe dem Hautmuskel zuwandern.

Nach 12 Stunden. Der Leukocytenwall hat an Dichte zugenommen; seine Lage ist im Allgemeinen wie vorher.

Nach 24 Stunden. Eine stärkere Demarcation hat nicht stattgefunden; auch sonst alles wie vorher.

\section{Breite, sehr tiefe Schnitte.}

Die Sehnitte gleichen im Ganzen den vorigen, nur dass hier noch der Hautmuskel durchschnitten bezw. so weit aus einander gewichen ist, dass der Boden des Schnittes vom Bindegewebe gebildet wird. Dies bedingt einen ganz wesentlichen Unterschied von dem vorigen Typus. Dort drangen die Bakterien selten von Anfang an auf dem Lymphwege weiter als bis zum Hautmuskel vor, da dieser viele Gefässe enthält, deren austretende Leukocyten den Bakterien den weiteren Weg versperrten. Bei den jetzt zu besprechenden Schnitten liegen ähnliche Verhältnisse vor, falls die unter dem Schnitte liegenden Bindegewebsfasern zufällig parallel mit dem Hautmuskel sind. Dann geschieht die Resorption längs des Hautmuskels an dessen Unterseite, wo ebenfalls sehr viele Leukocyten zuzuwandern pflegen. Führt dagegen ein Mal ein Bindegewebsbündel in die Tiefe, so werden natürlich auch die Bakterien leicht dorthin resorbirt werden; gleichzeitig werden aber die Gifte, die die Leukocyten anlocken, dadurch, dass sich die abführenden Lymphwege theilen, stark verdünnt und dadurch weniger wirksam.

Aussehen nach 4 Stunden. Im Corium befinden sich manchmal auffallend wenige Leukocyten; viele dagegen im Hautmuskel, direct unter diesem und im Bindegewebe und zwar hier nur zwischen den Fasern, die von der Basis der Wunde in die Tiefe führen, dagegen nicht in den- 
jenigen, die parallel zu ihr gehen und sie nicht berühren. Der Lenkocytenwall verläuft wie bei den breiten, tiefen Schnitten, nur ist er bei den Schnitten ohne Coagulum etwa doppelt so weit von der Oberfäche der Wunde entfernt. An den Ecken befinden sich ziemlich viele Leukocyten; dieselben wandern von dort aus in das Coagulum ein.

Ferner zeigen sich nun beträchtliche Unterschiede zwischen den inficirten und den nicht inficirten Schnitten, wie sie vorher schon in geringerem Grade beobachtet wurden. Man sieht öfters in grösserer Entfernung von der Wunde mitten im Bindegewebe Leukocytenhaufen, zu denen zwischen den dorthin führenden Bindegewebsfasern zahlreiche Leukocyten zuwandern (Taf. II, Fig. 9 u. 10); sie können auch von Punkten unterhalb der Infectionsstelle zu jenen Haufen in schräger Richtung zuwandern, während von diesen Punkten aus ein gerades Durchwandern quer durch die Bindegewebsfasern zur Infectionsstelle hin nicht stattfindet. In den erwähnten Haufen nun findet man bei starker Vergrösserung stets zahlreiche Bakterien, die in bestimmten Fällen sämmtlich phagocytirt sind. Die Leukocytenhaufen können von verschiedener Gestalt sein; meist sind sie länglichrund mit einer Spitze gegen die Infectionsstelle zu. Manchmal sieht man auch ganz nahe der Wunde den Bindegewebszügen entlang Leukocytenhaufen, in denen man stets Bakterien findet. - Leukocytenhaufen im Gewebe sind niemals bei nicht inficirten Schnitten zu sehen.

Nach 8 Stunden. Die Leukocyten haben entsprechend der Zeit. zugenommen. Die Häufchen, meist langgestreckt, sind nun in grösserer Zahl vorhanden; in sämmtlichen sind zahlreiche Bakterien zu sehen. Bei den sterilen Schnitten fehlen die Häufchen. Auch an den Ecken von Wunden sind sie vorhanden; auffallend ist ein Mal, dass ganz wenige Pneumokokken im Stande sind, einen sehr grossen Leukocytenhaufen hervorzurufen.

Nach 12 Stunden. Dieselben Vorgänge wie nach 8 Stunden. Manchmal Einwanderung in das Coagulum.

Nach 24 Stunden. Die Erscheinungen sind im Allgemeinen noch dieselben, nur ist der Wall jetzt breiter und dichter. Die Epidermis beginnt abwärts zu wachsen. In der Nähe der Infectionsstelle befinden sich dichte Leukocytenhaufen. $\nabla$ on einigen Besonderheiten ist noch Folgendes zu bemerken:

Die Milzbrandbacillen in der Wunde liegen parallel dem Wall und wachsen anscheinend ihm entlang; doch bleiben sie immer in einer bestimmten Entfernung; diejenigen, welche zwischen den Leukocyten liegen, sind zerfallen. 

wurde.

Betreffs der Tuberkelbacillen sei auf das verwiesen, was oben gesagt

Bei den Pneumokokkenschnitten (Taf. II, Figg. 11 u. 12) ist das ganze Bindegewebe weit hinaus dicht mit Leulocyten infiltrirt; zwischen diesen liegen ziemlich viele Kokken zerstreut, von denen nur wenige phagocytirt sind. Einige Kokkenhäufchen, die so gross sind, dass man auf sie schon bei 60 facher Vergrösserung aufmerksam wird, liegen nicht in Leukocytenhaufen, ja, nicht einmal von einem besonderen Leukocytenwall umgeben; es macht ganz den Eindruck, als ob die zuwandernden Leukocyten in der Nähe der erst erwähnten Kokken festgehalten würden.

\section{Schmale schnitte in's Bindegewebe.}

Bei den Schnitten in's Bindegewebe ist die Gelegenheit der Resorption in noch höherem Grade gegeben. - Die Schnittränder sind nur höchst selten mit einander verklebt, weshalb nur ein schmaler Schnitt beobachtet wurde.

Nach 8 Stunden. Staphylokokkenschnitt. Während der Schnitt oben zusammenliegt, sind die Wundränder unten durch eine grosse Menge eingewanderter Leukocyten aus einander gedrängt, die die sehr zahlreich, aber nicht dicht liegenden Kokken aufgenommen haben. Ein grösserer dichter Kokkenhaufen ist in geringem Abstand allseitig von Leulocyten umgeben:

\section{Breite Schnitte in's Bindegewebe.}

Die Schnitte klaffen in der Gegend des Hautmuskels weit aus einander, weniger weit, aber doch oft ziemlich stark im Bindegewebe. Manchmal sind ihre Ränder auch im Bindegewebe mit einander verklebt oder stehen sich wenigstens sehr nahe.

Aussehen nach 4 Stunden. In der Epidermis, im Corium und im Fettgewebe stehen die Leukocyten ungefähr ebenso wie früher. Dagegen steht an der unteren Seite der Wunde nicht mehr ein so regelmässiger Wall wie bisher, sondern entweder ist überhaupt kein ausgesprochener Wall vorhanden und die Leukocyten liegen regellos im Bindegewebe, oder der Wall verläuft äusserst unregelmässig. Die Zuwanderung der Leukocyten erfolgt dem Hautmuskel entlang an dessen Ober- und Unterseite; ferner wandern sie zahlreich aus dem Bindegewebe dorthin und zwar auf den Bindegewebszügen, die in ihrem weiteren Verlauf rom Schnitte durchtrennt sind. Da die Lage des Walles, so weit einer vorhanden ist, erst bei späteren Schnitten deutlich wird, sei sie erst dort besprochen. 
Nach 8 Stunden. (Taf. III, Fig. 16.) Die Zahl der Leukocyten hat zugenommen; die Zuwanderung erfolgt in derselben Weise wie nach 4 Stunden. Die Lage des Walles ist meist deutlich durch die Gestaltung der Oberfläche der Wunde bedingt; manchmal verläuft er ihr parallel, was besonders dann deutlich ist, wenn die Oberfläche der Bindegewebsschicht die Basis der klaffenden Wunde bildet und in das Bindegewebe nochmals ein schmaler Schnitt hineingeführt ist: dann verläuft der Wall genau parallel mit der Wundoberfläche in einigem Abstand und biegt auch um den schmäleren Theil des Schnittes in weitem Bogen herum.

In den Ecken und auch weiter im Bindegewebe befinden sich zahlreiche der oben beschriebenen Häufchen, falls die Schnitte inficirt waren; stets findet man bei stärkerer Vergrösserung zahlreiche Bakterien darin, von stark pathogenen (Pneumokokken) oft nur geringe Mengen, während in den Staphylokokken und Sarcinenhäufchen stets viele Bakterien vorhanden sind und wenige Staphylokokken keine Häufchenbildung hervorrufen, sondern von einzeln liegenden Leukocyten aufgenommen werden. Es rufen also hier wenige stark pathogene Bakterien dieselben Erscheinungen hervor wie viele nicht pathogene. Ferner sind die am weitesten in's Gewebe vorgedrungenen Staphylokokken stets von den auf demselben Wege herankommenden Leukocyten aufgenommen, während sie bei den pathogenen fast alle frei liegen.

Besonders auffallend sind ausserdem noch die Verhältnisse bei den Milzbrandschnitten. Liegen sehr viele Milzbrandbacillen im Bindegewebe - gleichgültig, ob in dem dort liegenden Coagulum oder in den Bindegewebs- oder Lymphspalten - so sind keine von unten zuwandernden Leukocyten zu sehen (Taf. III, Fig. 15). Oben im Fettgewebe und im Hautmuskel hat sich dagegen ein Wall gebildet und es dringen von dort aus vereinzelte Leukocyten nach unten in das Bindegewebe vor.

Nach 12 Stunden. Der Wall ist jetzt an den meisten Schnitten ausgebildet, aber in seinem Verlauf noch immer anscheinend so unregelmässig wie vorher. Besonders dringen Leukocyten in das Bindegewebe, das sich von unten zwischen die Wundränder geschoben hat, nicht vor, sondern grenzen es in gerader oder nach einwärts gebogener Linie $a b$. In den abgegrenzten Gebieten sind auffallend wenig Kerne zu sehen, auch zeigt das Bindegewebe eine verwaschene Färbung. Ueberall da, wo der Wall unterbrochen zu sein scheint, kann man finden, dass von dieser Stelle aus keine Bindegewebszüge direct zur Oberfläche führen. Leukocytenhäufchen mit Bakterien sind auch hier zahlreich zu sehen. Bei den in grosser Menge in das Bindegewebe eingedrungenen Milzbrandbacillen zeigt sich hier dasselbe wie nach 8 Stunden: zu der von dichtem 
BEITRÄGE ZUR LEHRE VON DER NATÜRLICHEN IMOTUNITÄT. I. 43

Haufen von Milzbrandbacillen durchsetzten Infectionsstelle und zu den Bacillenhaufen, die weiter im Gewebe liegen, wandern keine Leukocyten von unten längs der durchschnittenen Bindegewebszüge hin.

Nach 24 Stunden. Die Erseheinungen sind dieselben wie nach 12 Stunden; noch immer wandern - auch zu den nicht inficirten Suhnitten - neue Leukocyten zu. Die Epidermis beginnt sich von der Seite her unter den Leukocytenwall zu schieben.

\section{Zusammenfassung der Resultate.}

Bei den seichten, schmalen Schnitten haben sich schon nach 4 Stunden erhebliche Mengen von Leukocyten in der Nähe der Infectionsstelle angesammelt. Sie dringen entweder bis zu den Wundrändern vor und füllen die Wunde aus, oder sie machen in einiger Entfernung halt und bilden einen Wall um dieselbe. Auch in diesem Falle können einzelne oder viele Leukocyten an Stellen, wo Bakterien liegen, bis zu diesen rordringen. Die Leukocyten kommen theils von der Seite, theils von unten aus dem Hautmuskel und aus dem bezw. durch das entzündete Fettgewebe. Später nimmt der Wall nach unten an Breite und Dichte zu, während er gegen die Wunde zu gleich bleibt und nur die dort liegenden Leukocyten zerfallen. Zwischen der 12. und 24. Stunde löst sich die Wunde von der Haut völlig los.

Ein Unterschied zwischen inficirten und nichtinficirten Schnitten, oder zwischen solchen, die mit pathogenen und solchen, die mit nicht pathogenen Bakterien inficirt sind, ist bei 60 facher Vergrösserung nicht $\mathrm{zu}$ erkennen.

Die breiten, seichten Schnitte unterscheiden sich dadurch wesentlich von den schmalen seichten, dass bei ersteren der lieukocytenwall später auftritt, weniger dicht ist und oft nicht die ganze Wunde umzieht zu einer Zeit, wo es bei diesen schon der Fall ist. Es liegt hier also eher die Möglichkeit einer Resorption in die inneren Organe vor.

Bei den mitteltiefen Schnitten, die in das Fettgewebe, aber nicht bis auf den Hautmuskel gehen, wandern viele Leukocyten zu, gleichviel, ob die Schnitte inficirt sind oder nicht. Dieselben kommen theils aus dem Corium, theils von der Seite aus dem Fettgewebe, zum grössten Theil aus dem Hautmuskel her. Sie dringen manchmal bis zu den Wundrändern vor, öfter bilden sie einen Wall. Manchmal sind die 
Bakterien schon vor der Bildung des Walles in das tiefer liegende Gewebe gelangt; es folgt dann die Bildung eines zweiten Walles oder eines Leukocytenhaufens.

Infectionen in mitteltiefe Schnitte sind also viel gefährlicher; immerhin ist auch hier noch eine Beschränkung der pathogenen Bakterien auf die Wunde nicht ausgeschlossen.

Auch um tiefe Schnitte, die bis auf den Hautmuskel gehen, bildet sich von der vierten Stunde an immer zunehmend ein Leukocytenwall, der sich niemals bis zur freien Oberfläche erstreckt, und nur dann am Wundrand selbst liegt, wenn ein Coagulum in der Wunde ist. Muskelzüge u. s. w. werden von ihm quer durchbrochen.

Durchdrang der Schnitt auch den Hautmuskel, so wird zwar auch ein Leukocytenwall gebildet; dagegen sind die Resorptionsverhältnisse für die Bakterien so günstig, dass eine Infection mit stark virulenten Bakterien in solche. Wunden wohl stets tödtlich verläuft. Durch den fertig gebildeten Wall allerdings scheinen Bakterien nicht mehr durchdringen zu können. Um Bakterien, die in das Bindegewebe gedrungen sind, sammeln sich Leukocytenhaufen an.

Gehen die Schnitte bis in's Bindegewebe, so verläuft der Wall sehr unregelmässig; zwischen den mit pathogenen und den mit nicht pathogenen Bakterien inficirten Schnitten zeigen sich bedeutende Unterschiede.

\section{Schlussfolgerungen.}

Wird einem Thiere eine einigermaassen tiefe Wunde beigebracht und dieselbe mit Bakterien oder mit feinkörnigem Material inficirt, so werden diese theils auf dem Blutwege, theils auf dem Lymphwege resorbirt. Auf dem Blutwege gelangen sie durch das Herz in die Lunge und, soweit sie dort nicht hängen bleiben, in die übrigen Organe. Auf dem Lymphwege werden sie theils nach unten, theils nach der Seite resorbirt. Ausserdem bleibt ein grosser Theil der eingebrachten Materie in der Wunde selbst liegen.

Seichte Wunden. Etwas anderes ist der Verlauf, wenn dem Thiere nur eine seichte Wunde beigebracht wird, die die Epidermis nicht völlig durchtrennt. Hier konnte im mikroskopischen Präparate in den meisten Fällen keine Resorption nachgewiesen werden. Dann findet zunächst eine Vermehrung der Bakterien statt, besonders da, wo sie einzeln liegen; manchmal wachsen sie in die oberfächlichsten Theile des Gewebes hinein und werden nun erst weitergeschwemmt. Dies ist nur bis zur vierten Stunde nach der Infection möglich, da ron da an ein Leukocytenwall die 
Wunde umschliesst und ein Durchkommen hindert. Die Bakterien nehmen dann im Coagulum oder in Gewebsspalten in einiger Entfernung von den Leukocyten zu, wachsen aber nicht gegen den Wall hin, sondern parallel mit demselben ${ }^{1}$, bis sie schliesslich mit der ganzen Umgebung demarkirt und abgestossen werden. - Auf diese Weise kann auch eine Milzbrandinfection der Maus ohne Schaden verlaufen.

Resorption der Bakterien. Die Bakterien, die während oder kurz nach Beibringen der Wunde in's Gewebe gelangten, werden theils seitlich, zum grössten Theile aber nach unten resorbirt. Die seitliche Resorption wurde besonders bei Wunden am $\mathrm{Ohr}$, aber auch an der Rückenhaut beobachtet. Die Bakterien waren dann einzeln oder zu wenigen zusammenhängend ziemlich weit selbst bis in die obersten Epidermisschichten nachweisbar. Lebt dann das Individuum lange genug, so kann ausser der septischen Allgemeinerkrankung auch eine locale Affection entstehen, wie es z. B. bei der primären Pestpustel der Fall ist.

Weit häufiger tritt Resorption nach unten ein. Der Weg, den dabei die Bakterien nehmen, war am schönsten an einigen mit Zinnober inficirten Wunden nachweisbar, da die Körnchen desselben in sehr grosser Menge eingebracht wurden und ausserdem vielleicht wegen ihrer Grösse und ihrer Kanten und Härte langsam resorbirt werden (Taf. I, Fig. 1). Der Weg geht von der Epidermis in gerader oder schräger Richtung zu einer Stelle des Hautmuskels; dort passiren alle Partikelchen durch eine Lücke im Muskel und nehmen dann ihren weiteren Weg an der Unterseite des Muskels, oder der Zng theilt sich und die Hälfte wird an der Ober-, die andere an der Unterseite des Muskels resorbirt und geht diesem entlang. - Viele Bakterien, die in mitteltiefe Schnitte eingebracht wurden, waren übrigens auch in einiger Entfernung seitlich im Fettgewebe nachweisbar. ${ }^{2}$

Die Resorption der Bakterien und der Zinnoberkörnchen wird dadurch erleichtert, dass sich sehr bald die von der Wunde wegführenden Gewebsspalten erweitern. Diese Erweiterung kommt auch stets bei sterilen Schnitten vor und muss dann durch die von der Wunde aus resorbirten Secrete verursacht sein. Doch sind selbstverständlich auch die Stoffwechselproducte der Bakterien dazu im Stande. Da die Gifte gelöste

1 Vgl. damit die analogen Ergebnisse von Frank. S. 3.

2 Vielleicht werfen diese Beobachtungen einiges Licht auf die Bedentung der Agglutination. Agglatinirte Bakterien haften, anch wenn sie sich vermehren, fester zusammen; die Conglomerate, die sich dabei bilden, werden wegen ihrer Grösse nicht so leicht fortgeschwemmt und desbalb eher von den Leukocyten umgeben, wodurch dann eine AlJgep̣eininfection des Körpers verhindert wird. 
Substanzen sind, so werden sie selbstrerständlich schneller resorbirt werden als die Bakterien, die leichter irgendwo wenigstens für kurze Zeit hängen bleiben können. Sie unterscheiden sich ferner bezüglich ihrer Resorption von den Bakterien dadurch, dass sie in einem Gewebe, wo sie nach allen Seiten hin Abfluss haben, sich leichter vertheilen können und in Folge dessen verdünnt werden, während die Bakterien nur in geringerem Maasse verteilt werden. Ausserdem haben die Gifte als gelöste Substanzen die Fähigkeit, zu diffundiren, also nicht nur den Weg des Stromes zu machen, in dem sie fortgeführt werden, sondern sich auch seitlich zu verbreiten.

Vermehrung der Bakterien. Die an der Infectionsstelle liegen gebliebenen wie auch die resorbirten Bakterien haben grösstentheils die Fähigkeit, sich zu vermehren. Diese Eigenschaft konnte mit Sicherheit an den stark pathogenen Bakterien und den für die Maus nicht pathogenen Staphylokokken beobachtet werden, mit Wahrscheinlichkeit an der gelben Sarcine, unsicher blieb sie in den Heubacillen. Die Vermehrung auch nicht pathogener Bakterien an den Säften des lebenden Gewebes ist als Beweis anzusehen, dass dieselben den Bakterien einerseits genügend Nährstoffe bieten, andererseits keine balterientödtenden oder auch nur schädigenden Stoffe normaler Weise enthalten. Erstere Thatsache kann nicht auffallend erscheinen, da die untersuchten Bakterien die Fähigkeit haben, auf allen möglichen Nährböden zu wachsen, vor allem auf erstarrtem Blutserum; die gelbe Sarcine z. B. verflüssigt dasselbe kräftig. Allerdings ist damit noch nicht die Eigenschaft erwiesen, dass sie auch lebendes Eiweiss anzugreifen vermag. - Bact. coli z. B. ist nach den dahingehenden Untersuchungen dazu nicht fähig (16 u. 40). Doch ist zu bedenken, dass im Blute auch Stoffe verhanden sind, die von den Bakterien erfahrungsgemäss leicht angegriffen werden: beispielsweise enthält das menschliche Blut 0.1 bis 0.2 Procent Traubenzucker. - Auch die Thatsache, dass Insecten einer Infection mit Saprophyten zu erliegen pllegen (Balbiani 5), spricht dafür, dass auch viele apathogene Bakterien im lebenden Organismus zu wachsen vermögen.

Noch interessanter ist die Thatsache, dass in den lebenden, circulirenden Säften der Maus keine Stoffe sind, die die Bakterien tödten, oder wenigstens am Wachsthum verhindern. Hiergegen erscheint der Einwand berechtigt, dass vielleicht wenig Stoffe im Blute vorhanden sind: die nur einige Bakterien abtödteten und dabei gebunden würden, so dass sie für andere unschädlich wären. Wäre dies richtig, dann müssten gerade die äussersten Bakterien, zu denen diese Stoffe zuerst kommen, daron betroffen werden, während man in Wirklichkeit sieht, dass gerade das Gegentheil der Fall ist und gerade diese sich vermehren. Es ist also auch 
BeIträge zUR LeHRe vON DER NatÜRLICHEN InNMUNität. I. 47

aus diesen Versuchen zu schliessen, dass die bakterientödtenden Stoffe des Blutserums erst bei der Entnahme des Blutes entstehen in ähnlicher Weise wie das Fibrinferment.

Verhalten der Leukocyten. Schon 2 Stunden nach der Infection sind am Wundrande mehr oder weniger zahlreiche Leukocyten zu sehen. Dieselben treten, wie vielfach beobachtet werden konnte, an den der Wunde zugekehrten Seiten der Gefässe aus und wandern dann in den entzündlich erweiterten Bindegewebsspalten gegen die Wunde hin. Sie kommen längs der Epidermis (im Corium), quer durch das Fettgewebe und rór Allem dem Hautmuskel entlang, von dem aus sie in fast rechtem Winkel nach der Wunde abbiegen. Auch der Unterseite des Hautmuskels entlang wandern viele, um dann an einer Stelle, wo die Muskelfasern aus einander weichen, - meist direct gegenüber der Wunde oder an einem Orte, wo ein Gefäss liegt - durch ihn durchzutreten. Dies ist derselbe Weg, den die Gifte der Bakterien in umgekehrter Richtung machten, wie durch die Entzündung bewiesen wird, und den diese selbst machen; es ist aies leicht begreiflich, da es neben den Wundsecreten die resorbirten Gifte sind, die die Leukocyten anlocken.

Die Schnelligkeit, mit der die Leukocyten vordringen, ist ziemlich erheblich; sie ist nach den Messungen Leber's an der ausgeschnittenen Hornhaut des Meerschweinchens in $1 / 4$ bis $1 / 2$ Minute gleich ihrem eigenen Durchmesser, was in 1 Stunde $1 / 2$ bis 1 mm ausmacht.

Ueber die Ursachen, durch welche die Leukocyten nach der Infectionsstelle hingelockt werden, ist nach den classischen Untersuchungen von Leber nichts mehr zu bemerken. Sie können selbstverständlich nur in dem ron der Wunde ausgehenden chemischen Reiz bestehen, den die resorbirten Bakteriengifte und die Spuren gelösten Zinnobers, bezw. bei sterilen Wunden die autolytischen Zersetzungsproducte verursachen. Was die Menge der angelockten Leukocyten betrifft, so war sie bei den inficirten Schnitten kaum grösser als bei den sterilen; von ersteren waren vielleicht in den mit Schweinerothlauf inficirten am meisten zu sehen. Auf einige Besonderheiten betreffs der Menge der herangekommenen Leukocyten soll später noch eingegangen werden. Bemerkt sei noch, dass auch da, wo zahlreiche Bakterien weit im Gewebe liegen, sich ebenfalls Leukocytenhaufen um sie ansammeln, dass also nicht etwa die Wundsecrete die alleinige Ursache dazu sind.

Die Leukocyten dringen, wenn in der Wunde ein Blutcoagulum ist, bis zum Rande des Schnittes vor und vielfach in dieses hinein. Ebenso dringen sie, wenn die Wundränder an einander liegen, bis zu diesen vor. Flaffen dagegen die Wundränder weit, so stehen die Leuliocyten in geringem Abstand davon; dasselbe ist der Fall, wenn der Schnitt seicht ist. 
Auch kann es geschehen, dass durch einen schiefen Schnitt das die eine Seite begrenzende Gewebsstück keilartig hervorspringt; es wird dann von einem Leukocytenwall abgegrenzt, dessen Stellung einer senkrechten Linie entspricht, die von dem Ende des Schnittes auf die Epidermis gezogen wurde. Die Ursache für diese Vorgänge ist entweder die durch Ausstrahlung bedingte Temperaturerniedrigung oder die Austrocknung, die dann die anlockende Wirkung der resorbirten Substanzen überwiegt. Auf diese Weise entsteht dann ein Wall (Taf. I, Fig. 2), der sehon nach vier Stunden und dann immer dichter werdend die Wunde umgiebt. Das innerhalb dieses Walles gelegene Gewebe färbt sich schlechter und zeigt weniger Zellkerne als normales Gewebe. Uebrigens tritt der Wall nicht in voller Regelmässigkeit auf: es kann sein, dass, wenn auf dem Grunde oder am Rande einer seichten Wunde Bakterien liegen; die Leukocyten an dieser Stelle bis zu diesen vordringen. In solchen Fällen überwiegt dann die anlockende Wirkung der Bakterien über die abstossende der freien Oberfläche. - In späterer Zeit, etwa von der achten Stunde an, zeigen die am meisten nach dem Centrum zu gelegenen Leukocyten Degenerationserscheinungen, die sich in schlechterer Färbbarkeit der Kerne und schliesslichem Zerfall derselben kenntlich machen.

Die Folgen, die die Bildung des Walles hat, sind klar. Es wird dadureh die Resorption der Bakterien gehindert und diese schliesslich mit dem Walle selbst abgestossen. Ein Durchwachsen des Walles ron Seiten der Bakterien ist nicht möglich, im Gegentheil gehen sogar die in demselben liegenden zu Grunde. Auch flüssige Stoffe werden durch den Wall nicht resorbirt, wie die Versuche Noetzels (38) mit Tetanusgift beweisen.

Aufnahme der Bakterien. Diejenigen Bakterien, die über die Infectionsstelle hinausgedrungen sind und auch viele, die sich noch darin befinden, werden von den herankommenden Leukocyten aufgenommen. Dabei unterscheiden sich die Staphylokokken, Sarcinen, Heubacillen, Tuberkelbacillen und die Zinnoberkörnchen von den Pneumokukken, Milzbrandbacillen und Schweinerothlaufbacillen wesentlich insofern, als die Aufnahme bei ersteren stets und ausnahmslos stattfindet und meist nach 8 Stunden beendet ist, während die letzteren nur zum geringeren Theile aufgenommen werden. Im Folgenden soll zunächst die erstere Gruppe besprochen werden.

Nicht pathogene Bakterien. Die Phagocytose beginnt mit dem Momente, wo die Jeukocyten an dem Orte eintreffen, an dem sich die Bakterien befinden. Sie ist sehr lebhaft nach 4 Stunden; nach 8 Stunden sind kaum mehr freie Mikroorganismen übrig, nach 12 Stunden ist mit Sicherheit alles phagocytirt; nur in einem Falle (beim Einbringen von viel Zinnober tief in's Gewebe) wurden auch dann noch freie Körnchen 
gesehen, die aber nach 24 Stunden aufgenommen waren. Ob ein Mikroorganismus phagocytirt ist oder nicht, ist meist leicht zu erkennen, am besten an seiner Lage zum Kerne; die Bakterien liegen dann stets ganz nahe an demselben. Sind die Schnitte nicht zu dünn, so wird man auch selten im Zweifel sein, ob ein Mikroorganismus vielleicht ron dem dazu gehörigen Zellkerne durch die Schnittfläche getrennt ist. - Dicke Schnitte können die Beurtheilung erschweren. - Die am weitesten in's Gewebe eingedrungenen Balsterien sind stets aufgenommen, da sie auf demselben Wege resorbirt werden, auf dem die Leukocyten herankommen.

Die Ursache der Aufnahme ist keine andere als die der Anlockung. Wenn ein Leukocyt bis zu einem Mikroorganismus herangekommen ist, so sind noch nicht alle Theile seines Protoplasmas in möglichste Nähe desselben gebracht. Andererseits strömen von allen Seiten des Mikroorganismus chemisch wirkende Substanzen aus. Durch diese werden die abrigen Theile des Protoplasmas angelockt; sie schieben sich in Form amöboider Fortsätze vor, bis sie den Mikroorganismus ganz umgeben haben. Es ist daher die Aufnahme nicht im Mindesten von der Annäherung verschieden, sondern nur als eine Annäherung jedes einzelnen Theiles des Leukocyten zu betrachten.

Auch zur Frage, ob auch lebende oder nur todte Bakterien von den Leukocyten aufgenommen werden, können die vorliegenden Untersuchungen Beiträge liefern. Von vornherein ist das erstere viei wahrscheinlicher. In den Versuchen Leber's hat der Aspergillus, der enorme Jlengen von Lenkocyten anlockte, keine Spur von Absterbeerscheinungen gezeigt, sondern ist üppig weiter gewachsen, bis er durch den Leukocytenwall daran verhindert wurde. Es muss sich also in diesem Fall um Anlockung durch während des Lebens ausgeschiedene Stoffwechselproducte handeln. In unseren Versuchen konnte man allerdings sagen, dass unter den eingebrachten Bakterien viele todte waren; dagegen haben auch die weiter in's Gewebe eingedrungenen Bakterien Leukocyten angelockt und sind von diesen aufgenommen worden, ohne dass vorher Absterbeerscheinungen an ihnen wahrgenommen werden konnten; im Gegentheil konnte sogar Vermehrung constatirt werden. Uebrigens kann man sich leicht von der Phagocytose lebender Bakterien überzeugen, wenn man Meerschweinchen Bakterien mit Eigenbewegung, z. B. Typhusbacillen in die Bauchhöhle injicirt: man sieht dann nach einiger Zeit im Peritonealexsudat, wie das eine Ende eines Bacilius von einem Leukocyten gefasst ist, während er mit dem hinteren Ende noch lebhaft zappelt. Aus diesen Gründen, wie aus den vorhin angeführten Versuchen von Metschnikoff ist es als sicher anzunehmen, dass die Bakterien lebend aufgenommen werden. 
Betreffs der Phagocytose der hier besprochenen ersten Gruppe von Mikroorganismen wurde jedoch eine Ausnahme beobachtet. Wenn viele Bakterien, die einzeln leicht phagocytirt werden, in einem dichten, mässig grossen Haufen zusammenliegen, so werden sie nicht aufgenommen, sondern die Leukocyten halten sich in einem mehr oder minder grossen Abstand von ihnen (Taf. III, Fig. 13); dies ist auch dann der Fall, wenn die Bakterien nicht an der Oberfläche der Wunde liegen, sondern von Leukocyten von allen Seiten umgeben sind. Nur wenn die Häufchen wenig dicht sind, gehen sie bis zu ihnen hin und nehmen sie auf. Aehnliche Resultate erbielt Leber bei der Impfung von Staphylokokken auf die Hornhaut des Kaninchens, sowie bei der Impfung von Aspergillus, wo bei geringer Wachsthumsenergie das Mycel ron den Leukocyten direct eingehüllt wurde ohne Bildung eines Infiltrationsringes.

Die Ursache dafür ist keine andere als diejenige, die die Leukocyten zu der Infectionsstelle anlockt, nur wirkt sie hier in viel stärkerer Concentration als in der Ferne, oder in der Nähe von wenigen Koklien. Jede Substanz aber, die in geringer Concentration reizend wirkt, wirkt in starker Concentration lähmend, wie dies beispielsweise für die Leukocyten von der Chininwirkung, für andere Zellen von sehr vielen Giften nachgewiesen ist. So sagt auch Leber von der Ursache, warum die Leukocyten direct um die Infectionsstelle bewegungslos und meist abgestorben sind, dass dieselbe Substanz, die in geringerer Concentration eine erregende (anlockende) Wirkung ausübt, in stärkerer Concentration lähmt.

Die Leukocyten dringen also bis zu ibrem Concentrationsoptimum ror, das bei grossen Kokkenhaufen in einiger Entfernung von diesen liegt und bleiben dort liegen. Doch vermehrt sich die Menge des Giftes in der Nähe der Haufen, da immer neues producirt wird und dasselbe zum grössten Theile nicht abfliessen kann, da durch den Leukocytenwall die Resorption gehindert wird. Die Leukocyten können nicht zurück, da immer neue nachdringen und erliegen dem Einfluss des Giftes. Andererseits ist es auch wahrscheinlich, dass die zurückgehaltenen Stoffwechselproducte den Bakterien selbst schädlich werden.

Stark pathogene Bakterien. Die Mikroorganismen der zweiten Gruppe, nämlich Pneumokokken, Milzbrandbacillen und Schweinerothlaufbacillen, unterscheiden sich von den eben besprochenen dadurch, dass sie nur zum kleinen Theil von den herangekommenen Leukocyten aufgenommen werden. Es ist dies eine höchst auffallende Thatsache, da sonst alle möglichen eingebrachten Partikelchen phagocytirt werden, wie, um nur einige davon zu nennen, Zinnober, chinesische Tusche, Schwerspath, 
Goldstaub, fein vertheiltes Platin, Oel, selbst Crotonöltröpfchen, Schimmelsporen, lebende und todte Bakterien. Wenn also díe erwähnten Mikroorganismen an der Infectionsstelle zum grössten Theile nicht aufgenommen werden, so muss dafür eine besondere Ursache vorliegen. Am einfachsten ist es, anzunehmen, dass es dieselbe ist, die die Leukocyten hindert, bis in die Nähe sehr dichter Staphylokokkenhaufen vorzudringen und dieselben aufzunehmen. Als Ursache dieser Erscheinung musste die Wirkung eines Giftes angenommen werden, das in geringer Dosis reizend, in stärkerer lähmend wirkt, so dass die Leukocyten nur soweit herankommen, als sie seine Concentration vertragen. Es würde demnach auch hier anzunehmen sein, dass die Leukocyten durch ein Gift bis auf eine gewisse Entfernung, selbst ganz nahe an die Bakterien angelockt werden, dass aber die Aufnahme derselben unterbleibt. Die stark pathogenen Mikroorganismen würden sich also dadurch von den nicht pathogenen unterscheiden, dass sie einzeln oder in geringer Zahl ein Gift produciren, dessen Wirkung dem von vielen Bakterien der ersten Gruppe gleichkommt. Ein solches Gift konnte allerdings beim Milzbrand noch nicht nachgewiesen werden; doch spricht für sein Vorhandensein, abgesehen ron dem Fieber, die Nekrose, die an der Infectionsstelle beim Menschen besteht.

Auffallend mag es immerhin erscheinen, dass die Leukocyten oft bis ganz nahe an die Bakterien herankommen und nur den letzten Schritt, die Phagocytose, unterlassen. Auch dies lässt sich mit der oben gegebenen Erklärung der Phagocytose vereinbaren. Die Gifte wirken in einiger Entfernung viel schwächer als in der Nähe. Bei der Annäherung nimmt ihre Wirkung zu, doch wirkt immer nur ein Theil davon, da sie auch nach anderen Seiten fortgeschwemmt werden. Bei der Aufnahme dieser Mikroorganismen würde aber das gesammte Gift wirken, eine Menge, die das Concentrationsoptimum überschreitet.

Liegen die Bacillen mehr einzeln, so zeigt sich also die Giftwirkung darin, dass sie von den Leukocyten nicht aufgenommen werden; liegen sie in grossen Haufen, so tritt die Erscheinung der Lähmung noch auf andere Weise zu Tage. Während sich die Leukocyten dichten Haufen nicht pathogener Bakterien wenigstens auf eine geringe Entfernung nähern, kommen sie entsprechend der grösseren. Giftigkeit der stark pathogenen überhaupt nicht heran, wie z. B. beim Milzbrand beschrieben wurde. Diese Erscheinung tritt besonders bei tiefen Schnitten zu Tage: es sind hier nach 8 und 12 Stunden beim Einbringen von vielen Milzbrandbacillen keine zuwandernden Leukocyten zu sehen (Taf. III, Figg. 15 u. 16), während sie bei dem gleichen Infectionsmodus bei nicht pathogenen Bakterien in grosser Menge herankommen. Eine weitere Erscheinung, die in 
der gleichen Weise zu deuten ist - allerdings nur einmal bemerkt wurde -, ist folgende: Wenn in der Nähe eines Gefässes sich dichte Milzbrandhaufen befinden (Taf. III, Fig. 14), so findet die Auswanderung der Leukocyten an den von ihnen abgewendeten Seiten statt, während die Leukocyten sonst immer an der der Infectionsstelle näheren Seite austreten. - Diese beiden Vorgänge finden übrigens nur bei Einimpfung grosser Mengen statt und konnten deshalb auch nur bei Milzbrand beobachtet werden.

Die untersuchten nicht pathogenen und pathogenen Bakterien unterscheiden sich also auf folgende Weise: Erstere secerniren ein Gift, das in mässigen Mengen die Leukocyten anlockt bis zur Phagocytose und sie erst in solchen Nengen lähmt, wie sie nur von sehr vielen Baliterien producirt werden; auch dann ist das Gift noch so schwach, dass die Wirkung sich nur auf geringe Entfernung erstreckt. Das Gift der pathogenen Bakterien wirkt ebenfalls anlockend, doch zeigt sich die lähmende Wirkung schon in geringeren Dosen, indem die Leukocyten nicht bis zu den Bakterien herankommen oder sie wenigstens nicht aufnehmen. In grösseren Dosen wirkt das Gift schon auf die Entfernung lähmend. Der Unterschied beruht also nur auf grösserer und geringerer Intensität des producirten Giftes und die Wirkungen desselben sind nicht principiell, sondern nur quantitativ verschieden. Es scheint daher der Ausdruck "negative Chemotaxis" nicht passend gewählt, da er eine principiell verschiedene Wirkung präjudicirt; besser dürfte der Ausdruck ,Hyperchemotaxis" am Platze sein. Dass diese Bakterien überhaupt anlockend wirken, geht daraus hervor, dass auch dort, wo sie in geringerer Menge weiter in's Gewebe resorbirt werden, sich Leukocyten um sie ansammeln.

Auch unter den Mikroorganismenarten, die gewöhnlich nicht aufgenommen werden, befinden sich meist einige Individuen, die der Phagocytose verfallen. Bei der Erklärung dieser Thatsache ist an zwei Möglichkeiten zu denken: entweder es sind nur manche Leukocyten im Stande, auch stärker virulente Bakterien aufzunehmen, oder es sind manche Bakterien anders als die Mehrzahl beschaffen, so dass sie leichter aufgenommen werden können. Beides dürfte wohl der Fall sein. Für das erstere spricht, dass die betreffenden Leukocyten gleich mehrere Bakterien aufgenommen haben; die letztere Annahme wäre mit Metschnikoff so zu erklären, dass sich unter den eingebrachten Bakterien wohl auch weniger virulente befinden. In jeder Milzbrandcultur kann man zerfallene Bacillen nachweisen; von den Pneumokokken ist es bekannt, dass sie auf künstlichen Nährböden schon nach wenigen Generationen ihre Virulenz verlieren und es ist wohl denkbar, dass dies erst bei einigen, dann bei allen Individuen geschieht. 
Es ist hier noch einiger Einwände zu gedenken, die gegen die Annahme gemacht worden sind, dass die Phagocytose eine Schutzwirkung des Körpers darstellt. Zunächst wurde der Einwand gemacht, dass gerade die nicht pathogenen Bakterien aufgenommen werden, die pathogenen nicht, wäbrend sich doch gerade diesen gegenüber eine Schutzwirkung entfalten müsste. Dagegen betonte Metschnikoff, dass diese Bakterien gerade deshalb pathogen wirkten, weil sie nicht aufgenommen würden, die anderen nicht mehr pathogen wirken könnten, weil sie aufgenommen würden. Auch der Einwand, dass bei manchen tödtlich verlaufenden Infectionskrankheiten reichliche Phagocytose vorkommt, und die Thiere trotzdem zu Grunde gehen, ist nicht stichhaltig, da einerseits auch viele freie Bakterien in solchen Fällen vorhanden sind, und vor Allem eine Abtödtung der aufgenommenen Bakterien nicht nachgewiesen werden konnte; diese Abtödtung durch die Zellen ist aber das hauptsächliche Moment für den Selbstschutz des Körpers. Ausserdem muss eine im Verlauf der Krankheit auftretende Phagocytose als eine während der Krankheit erworbene Eigenschaft aufgefasst werden, und gehört dann wie jede Heilung einer Krankheit zur erworbenen Immunität, während hier nur die natürliche Immunitât, und somit nur die Verhältnisse gleich im ersten Beginn des Eindringens der Bakterien, besprochen werden sollen.

Folgen der Phagocytose. Aus der Thatsache, dass gerade diejenigen Bakterien, die nicht pathogen wirken, der Phagocytose zum Opfer fallen, ist zu schliessen, dass zwischen beiden Erscheinungen eine engere Beziehung besteht. Es erübrigt nur noch, die Folgen der Phagocytose in Erwägung zu ziehen, um den richtigen Zusammenhang zwischen beiden Thatsachen zu finden, da selbstverständlich die Aufnahme in eine Zelle an sich nicht genügend erscheint, um die weitere Vermehrung eines Mikroorganismus zu verhindern.

Die Phagocytose verhindert schon mechanisch eine schnellere Ausbreitung der Bakterien, indem die Leukocyten als grössere Körper nicht so leicht fortgeschwemmt werden wie einzelne Bakterien. Doch ist, um die Gefahr des Eindringens vollständig zu verhindern, eine Abtödtung der aufgenommenen Bakterien nöthig. Diese Abtödtung scheint in manchen Fällen aus irgend welchen Gründen nicht stattzufinden, wie z. B. bei der Gonorrhöe. Möglicher Weise ist dabei auch die Einwirkung zu kurz. In den untersuchten Präparaten konnte sie mehrmals mit Sicherheit nachgewiesen werden. Nach 24 Stunden zeigten Milzbrandbacillen die intracellulär lagen, degenerirte Formen, während die von ihnen entfernt liegenden gut gefärbt waren. Bei den Staphylokokken bonnten Zerfallsformen nach 14 Tagen nachgewiesen werden. Bei anderen Versuchen, 
wie bei den Sarcinen, fanden sich manchmal nach 24 Stunden Leukocytenhäufchen im Gewebe, die keine Bakterien enthielten. Waren die Thiere nach kürzerer Zeit getödtet worden, so hatten ausnahmslos in solchen Häufchen mindestens viele Leukocyten Bakterien aufgenommen und die Häufchen müssen sogar dadurch entstanden sein, dass an dieser Stelle Bakterien lagen, die die Leukocyten anlockten. Es ist daher anzunehmen, dass auch diese Häufchen so entstanden sind und nach 24 Stunden die Baiterien schon zu Grunde gegangen waren. Dieses Zugrundegehen ist leicht verständlich, da die bakterientödtenden Stoffe, die aus den Leukocyten stammen, in ihnen sicher in concentrirterem Maasse vorhanden sind und dementsprechend mehr zur Wirkung kommen. Doch kommt ihre Wirkung auch ausserhalb der Leukocyten zur Geltung. Nit Sicherheit wurde das extracelluläre Zugrundegehen an Milzbrandbacillen beobachtet, die in Leukocytenhaufen lagen; andererseits ist auch die Gewebseinschmelzung als Wirkung der Leukocyten nachgewiesen. Diese Einwirkung auf Bakterien wurde aber nur dann beobachtet, wenn diese in dichten Leukocytenhaufen lagen. $\mathrm{Ob}$ die beiden Wirkungen, die extracelluläre $\mathrm{Ab}$ tödtung und die Gewebseinschmelzung durch lebende oder durch abgestorbene Leukocyten zu Stande kommt, konnte nicht mit Sicherheit entschieden werden.

Verhalten der Bakterien in den Organen. Wie vielfache Untersuchungen ergaben (vergl. darüber die Litteratur bei Tiede ([57]) finden sich die eingebrachten Bakterien schon nach wenigen Minuten in den inneren Organen vor. Sie nehmen dort an Zabl zu bis zu $3 / 4$ Stunden nach der Impfung; dann folgt eine Abnahme; bei septicämisch wirkenden Bakterien folgt darauf eine Zunahme, die bis zum Tode andauert. Von allen Untersuchern ist diese Thatsache darauf zurückgeführt worden, dass einerseits Babterien in den inneren Organen zu Grunde gehen, andererseits neue resorbirt werden; Anfangs überwiegt die Resorption, nach einiger Zeit, wenn sie aufhört, die Abtödtung, bis nur noch die virulentesten übrig sind, die sich vermehren. Diese Zeitangaben stimmen mit unseren Versuchen insofern überein, als schon nach 2 Stunden Leukocyten an der Infectionsstelle waren, und sicher schon früher dorthin unterwegs waren und die entgegenkommenden Bakterien an weiterem Vordringen behinderten.

Directe Beobachtungen über die Art des Unterganges der Bakterien in den Organen wurden nicht gemacht; sicher geschieht derselbe aber nicht durch das Blutplasma, da auch nicht pathogene Bakterien sich an der Infectionsstelle im Blutplasma vermehren. Viel wahrscheinlicher ist es, dass auch hier die Abtödtung durch die Leukocyten stattfindet, wie auch 
die Eingangs erwähnten Cntersuchungen, vor allem die von $W$ erigo und von Zilberberg und Zelion y beweisen. Denn die an den Gefässwänden hängen gebliebenen Bakterien sind dadurch nicht etwa vor der angeblichen bakterientödtenden Wirkung des Blutes gesehütat - da sie ja mit dem grössten Theile ihrer Obertläche in dasselbe hineinragen -, sondern im Gegentheil der Wirkung der Leukocyten ausgesetzt: eine Phagocytose ist dort sehr leicht möglich, da sich die Leukocyten sehr langsam, etwa 10 bis $12 \mathrm{Mal}$ langsamer als die rothen Blutkörperchen fortbewegen. Dieses langsame Fortkriechen längs der Gefässwand geschieht bekanntlich nicht nur in den Capillaren, sondern auch in den kleinen Arterien und Venen in dem Poiseuille'schen Raum, so dass auch hier die beste Gelegenheit zur Phagocytose ist. -

Die vorliegenden Untersuchungen sollten sich nur auf einige der Eragen erstrecken, wie sich das Verhältniss zwischen Bakterien und Organismus an der Infectionsstelle gestaltet. Ich bin mir bewusst, dass hierbei nur die Extreme behandelt worden sind, nämlich das Verhalten nicht pathogener Bakterien einerseits und hochvirulenter andererseits; die Mittelformen, progrediente Eiterungen, entzündliches Oedem u. s. w. wurden nicht berührt. Nach den Eingangs erwähnten Untersuchungen scheinen aber auch hier nur die Leukocyten in Betracht zu kommen, weniger durch Phagocytose als durch Umlagerung der Bakterien. Doch ist es in solchen Fällen schwer zu entscheiden, ob es sich um Heilung durch sehon vorher vorhanden gewesene Kräfte oder um Heilung durch während der Krankheit neu gebildete Stoffe handelt, in welch' letzterem Falle der Process zur erworbenen Immunität gehören würde.

Aus den vorliegenden Untersuchungen geht hervor, dass die Ursache für die natürliche Immunität nicht in den Säften des Körpers präformirt vorhanden ist, indem sich in derselben auch nicht pathogene Mikroorganismen vermehren können, sondern dass sie allein in den Leukocyten zu suchen ist, die die Bakterien durch Phagocytose oder Umzingelung unschädlich machen und schliesslich abtödten. Andererseits beruht die Virulenz eines Mikronrganismus nicht allein auf seiner Widerstandsfähigkeit gegen die Schutzkräfte des Körpers, sondern vor Allem auf dem Grade seiner Giftigkeit, die die Leukocyten verhindert, ihn aufzunebmen oder dicht zu umgeben.

Abgeschlossen Februar 1903. 


\section{Litteratar-Verzeichniss.}

1. Afanassieff, Ueber die Bedeutung des Granulationsgewebes bei der Infection mit pathogenen Mikroorganismen. Centralblatt für allgem. Pathologie. Bd. VII. Ref. nach Baumgarten's Jahresbericht. 1896. S. 736.

2. Derselbe, Ueber die Bedeutang des Granulationsgewebes bei der Infection vou Wunden mit pathogenen Mikroorganismen. Ziegler's Beiträge. Bd. XXII. S. 11.

3. Alesander-Iewin, Zur Histologie der acuten bakteriellen Entzün Iungen Arbeiten a. d. Gebiete der path. Anatomie u. Bakteriol. a. d. path.anat. Institut zu Tïbingen. - Ref. nach Baumgarten's Jahresbericht. 1891. S. 537.

4. Almquist, Zur Phagocytose. Diese Zeitschrift. Bd. XXXI. S. 507.

5. Balbiani, Comptes rendus de l'Acad. des Sciences. - Ref. nach Metschnikoff, Pathologie comparée de l'inflammation. S. 103.

6. Besredka, L'immunité dans l'intection typhique expérimentale. Annales de l'Institut Pasteur. 1901. p. 209.

7. Derselbe, Rôle des leacocytes dans l'intoxication par une combinaison sulfuré: d'arsenic. Ébenda. 1899. p. 49.

8. Bitter, Ueber die Verbreitung des Vaccins u. s. w. Diese Zeitschrift. Bd. IV. S. 299.

9. Bordet, Recherches sur la phagocytose. Annales de l'Institut Pasteur. 1896. p. 104 .

10. Derselbe, Sérum ant streptococcique. Ebenda. 1897. p. 177.

11. Buchner, Die chemische Reizbarkeit der Leukocytea und deren Beziehung zur Entzündung und Eiterung. Berliner klin. Wochenschrift. 1890. S. 1084.

12. Bumm, Ueber die Einwirkung pyogener Mikroorganismen auf's Bindegewebe. - Cit. nach Baumgarten's Jahresbericht. 1888. S. 396.

13. v. Christmas-Dirckinck-Holmfeldt, Ueber Immunität u. Phagocytose. Fortschritte der Medicin. 1887. S. 401 u. 583.

14. Czaplewski, Untersu'hungen îber die Immunität der Tauben gegen Milzbrand. Ziegler's Beiträge. Bd. VII. S. 47.

15. Derselbe, Weitere Untersuchungen über die Immunitït der Tauben gegen Milzbra!d. Diese Zeitschrift. Bd. XII. S. 348.

16. Dieudonné, Ueber das Verhalten des Bacterium coli zu nativem und denaturirtem Eiweiss. Hygien. Rundschau. 1902. S. 897.

17. Durham, The mechanism of reaction to peritoneal infection. - Cit. nach Baumgarten's Jahresbericht. 1897. S. 910.

18. van Ermengem, Phagocytose et Bactériotherapie. - Cit. vach Baumgarten's Johresbericht. 1888. S. 428. 
BeITRÄGE ZUR LEHRE VON DER NATÜRLICEEN IMMUNTTÄT. I. 57

19. Frank, Ueber den Untergang der Milzbrandbacillen im Thierkörper. Centralblatt für Bakteriologie. Bd. IV. S. 710.

20. Gabritschewsky, Propriété chimiotactiques des leucocytes. Annales de l'Institut Pasteur. 1890. p. 346.

21. Hess, Untersuchungen zur Phagocytenlehre. Virchow's Archiv. Bd. CIX. S. 365 .

22. Derselbe, Weitere Untersuchungen zar Phagocytenlehre. Ebenda. Bd. CX. S. 313.

23. Hohnfeldt, Ueber die Histogenese der bei Staphylococcus-Invasion hervorgerufenen Bindegewebsabscesse. Ziegler's Beiträge. Bd. III. S. 343.

24. Leber, Die Entstehung der Entzündung. Leipzig 1891.

25. Liakhovetsky, Sur les phénomènes provoqués etc. - Cit. nach Baumgarten's Jahresbericht. 1895. S. 142.

26. Lubarsch, Untersuchungen über die Ursachen der angeborenen und erworbenen Immunität. Berlin 1891.

27. Marchand, Études sur la phagocytose des streptocoques atténuẹs et virulents. - Cit. nach Baumgarten's Jahresbericht. 1898. S. 21.

28. Martel, Le charbon du chien. Annales de l'Institut Pasteur. 1900. p. 13.

29. Massart, lue chimiotaxisme des leucocytes et l'immunité. Ebenda. 1892. p. 321 .

30. Massart et Bordet, Recherches sur l'irrabilité des leucocytes etc. Note présentés à la Soc. royale de Bruxelles. 1890.

31. Dieselben, Le chimiotaxime des leucocytes et l'infection microbienne, Annales de l'Institut Pasteur. 1891. p. 417.

32. Mesnil, Sur le mécanisme de l’immunité contre la septicémie vibrionienne. Ebenda. 1896. p. 369 .

33. Metschnik off, Virchow's Archiv. Bd. XCVII. - Cit. nach Bitter, Diese Zeitschrift. Bd. IV. S. 397.

34. Derselbe, Etudes sar l'immunité. II. Le charbon des pigeons. Annales de 'l'Institut Pasteur. 1890. p. 65.

35. Derselbe, Etudes sur l'immunité. III. Le charbon des rats blancs. Ebenda. p. 193.

36. Derselbe, Etudes sur l'immunité. VI. Sur la destruction extracellulaire des bactéries dans l'organisme. Ebenda. 1895. p. 448.

37. Netschajeff, Ueber die Bedeutung der Lenkocyten bei Infection des Organismus durch Bakterien. Virohow's Archiv. Bd. CXXV. S. 415 .

38. Noetzel, Jeber die Infection granulirender Wunden. Fortschritte der Medicin. 1898.

39. Nuttall, Experimente über die bakterienfeindlichen Einflüsse des thierischen Körpers. Diese Zeitschrift. Bd. IV. S. 353.

40. Pfanndler, Ueber das Verhalten des Bacterium coli commune zu gewissen Stickstoffsubstanzen und zur Stärke. Centralblatt für Bakteriologie. Bd. XXXI. S. 113.

41. Pfoehl, Chemotaxis der Leukocyten in vitro. Ebenda. Bd. XXIV. S. 343.

42. Pierolini, Sur la phagolyse dans la cavité péritonéale. Annales de l’Institut Pasteur. 1897. p. 308.

43. Podbelsky, L'immunité vis-à-vis du bacillus subtilis. Ebenda. 1898. p. 427.

44. Radziewsky, Beitrag zur Kenntniss des Bacterium coli. Diese Zeitschrift.

Bd. XXXIV. S. 368. 
45. Radziewsky, Untersuchungen zur Theorie der bakteriellen Infection. Diese Zeitschrift. Bd. XXXVII. S. 1.

46. Ribbert, Der Untergang pathogener Schimmelpilze im Rörper. Bonn 1887.

47. Derselbe, Der jetzige Standpunkt der Lehre von der Immunität. Deuische med. Wochenschrift. 1890 . S. 690 .

48. Rogowitsch, Zur Kenntniss der Wirkung des Rauschbrandbacillus auf den thierischen Organismas. Zi egler's Beiträge. Bd. IV. S. 291.

49. Ruffer, On the destruction of mieroorganisms during the process of inflammation. - Cit. nach Centralblatt für Bakteriologie. Bd. IX. S. 740.

50. Derselbe, Einige Versuche über den Mechanismus der natürlichen und künstlichen Imınnität. Ebenda. Bd. XI. S. 117.

51. Derselbe, Recherches sur la destruction des microbes par les cellules amiboïdes dans l'inflammation. Annales de l'Institut Pasteur. 1891. S. 673.

52. Sawtschenko, Contribution à l'étude de l'immunité. Ebenda. 1897. p. 865.

53. Schattenfroh, Ueber die Beziehungen der Phagocytose zur Alexinwirkung bei Sprosspilzen und Bakterien. Archiv für Hygiene. Bd. XXVII. S. 234.

54. v. Sicherer, Chemotaxis der Warmblüter-Leukocyten ausserhalb des Körpers. Münchener med. Wochenschrift. 1896. S. 976.

55. Derselbe, Zur Chemotaxis der Leukocyten in vitro. Centralblatt für Bakteriologie. Bd. XXVI. S. 360.

56. Silvestri, Ricerche sperimentali sulla cheratite settica. - Cit. nach Bara m garten's Jahresbericht. 1891. S. 538.

57. Tiede, Wann lassen sich die Erreger des Rothlaufs and der Geflügelcholera nach einer Hautimpfung in den inneren Organen von Mäusen nachweisen? Inaug.Dissertation. Giessen 1902.

58. Trapeznikoff, Du sort des spores des microbes dans l'organisme animal. Annales de l'Institut Pasteur. 1891. S. 362.

59. Unna, Die Einwanderung der Staphylokokken in die mensehliche Haut. Deutsche Medicinalzeitung. 1896. - Cit. nach B a ungarten's Jahresber. 1896. S. 46.

60. Vaillard et Vincent, Contribution à l'étude du tétanos. Annales de l'Institut Pasteur. 1891. S. 1.

61. Vejnar, Ein experimenteller Beitrag zu der Lehre von der intracellulären Vernichtung der Mikroben durch die Lenkocyten. Allgemeine Wiener med. Zeitung. 1892.

62. Wallgren, Experimentelle Untersuchungen über peritoneale Infection mit Streptokokken. Ziegler's Beiträge. Bd. XXV. S. 206.

63. Wassermann, Ueber die Orsachen der natürlichen Widerstandsfähigkeit gegenüber gewissen Infectionen. Deutsche med. Wochenschrift. 1901. S. 4.

64. Werig 0 , La chimiotaxe négative des leakocytes et des phagocytes en général.

- Cit. nach Centralblatt für Bakteriologie. Bd. XXXI. Ref. S. 95.

65. Wolfheim, Ein weiterer Beitrag zur Phagocytenlehre. Ziegler's Beiträge. Bd. III. S. 405 .

66. Zillerberg und Zeliony, La chimiotaxie négative des leucocytes etc. Annales de l'Institut Pasteur. 1901. p. 615. 


\section{Erklärung der Abbildungen. \\ (Taf. I-III.)}

(Sämmtliche Präparate, ausser Fig. 18, sind von Infectionsstellen der weissen Maus angefertigt.)

\section{Tafel I.}

- Fig. 1. Resorption von Zinnoberkörnchen durch das Fettgewebe in einer fast continuirlichen Linie; 8 Standen post infectionem. Hämatoxylin $7 \% / 1$.

Fig. 2. Infection mit grossen Mengen von Staphylokokken in einen seichten Schnitt; nach 12 Stunden. Dichter Leukocytenwall um die Infectionsstelle in geringem Abstande von dem Staphylokokkenhaufen. Lithioncarmin. Gram 7\%/.

Fig. 3. Bis in's Fettgewebe reichender Schnitt, mit Pneumokokken inficirt; nach 8 Stunden. Die Leukocyten stehen in dem Walle nicht so dicl.t wie bei Fig. 2, da die Fettzellen als Lücken zwischen ihnen frei bleiben. Lithioncarmin-Gram $70 / 1$.

Fig. 4. Nicht inficirter, tiefer, klaffender Schnitt; nach 12 Stunden. Um den Schnitt hat sich ein Leukocytenwall gebildet, der auch den Hantmuskel senkrecht durchbricht und uberall in geringem Abstande von der Oberfläche bleibt, da in der Wunde kein Coagulum liegt. (Das Hautstückchen hatte sich bei der Härtung nach innen umgerollt, so dass unten am Photogramm ebenfalls ein Theil der Epidermis $z \mathbf{n}$ sehen ist.) Lithionearmin $70 / 1$.

Fig. 5. Mit Staphylokokken inficirter seichter Schnitt; nach 24 Stunden. Unter dem Leukocytenwalle ist das Epithel durchgewachsen und hat die ganze Wundstelle demarkirt. Ein Theil des Coriums und des Fettgewebes ist noch immer entzündlich verändert. Lithioncarmin-Gramn $7 \%$.

Fig. 6. Infectionsstelle von einer Maus, die in der gewöhnlich üblichen Weise mit Staphylokokken in eine Hauttasche inficirt wurde; nach 12 Stunden. Um die (im Präparate ungefärbten) Kokken hat sich ein dichter Leukocytenwall gebildet, zu dem noch neue Leukocyten zuwandern. Lithioncarmin ${ }^{32} j_{1}$.

Tafel II.

Fig. 7. Infection mit Milzbrand in einen seichten Schnitt; nach 8 Stunden. Um die Wunde hat eine reichliche Lenkocytenansammlung stattgefunden; von der Wunde aus sind durch den Hantmuskel Milzbrandbacillen in die zwischen Bindegewebe und Muskel liegende Spalte resorbirt worden; zu diesen wandern von unten Leukocyten zu, so dass jenseits des Hautmuskels ein neuer Wall entsteht. Lithioncarmin-Gram 7\%. (Die Verbältnisse bei Infection mit grossen Mengen Milzbrandbacillen zeigt Fig. 15.) 
60 Karu Kisskalt: Beiträge zUR LeHre v. D. NatürI. ImMUnität. I.

Fig. 8. Infection mit Staphylokokken nach \& Stunden. Lebhafte Phagocytose. (Beim Drehen der Mikrometerschraube war zu sehen, dass anch diejenigen Kokken, die hier anscheinend noch frei liegen, phagocytirt sind.) Lithioncarmin-Gram \$20/1.

Fig. 9. Infection mit Sarcinen in einen tiefen Schnitt; nach 4 Stunden. Von der Wunde aus (links) sind zahlreiche Sarcinen in das Gewebe resorbirt worden; um diese hat sich (rechts) ein Leukocytenhaufen gebildet. Lithioncarmin-Gram $70 / 1$.

Fig. 10. Dieselbe Stelle. Sämmtliche in dem Leukocytenhaufen liegende Sar. cinen sind phagocytirt. Bísmarekbraun-Gram ${ }^{800} /$. $^{*}$

Fig. 11. Infection mit Pneumokokken in eine tiefe Wande (links); nach 24 Stunden. Die Pneumokokken haben sich im ganzen Bindegewebe u. Fettgewebe ; verbreitet; dasselbe ist dicht mit Leukocyten infiltrirt. Lithioncarmin-Gram $70 /{ }_{1}$.

Fig. 12. Eine Stelle aus dem Bindegewebe im vorigen Präparate. Trotz der Anwesenheit zahlreicher Leukocyten sind nur sehr wenige Pneumokokken phagocytirt; die meisten ziehen sich zwischen ersteren durch. Bismarckbraun-Gram ${ }^{800 / 1}$.

\section{Tafel III.}

Fig. 13. Infection mit vielen Staphylokokken in einen tiefen Schnitt; nach 8 Stunden. Obwohl die Kokken nicht am äussersten Rande der Wunde liegen, sondern dieselbe mit einem Blutcoagulum (oben) ausgefüllt war, gehen die Leukocyten doch nicht bis zu ihnen hin, sondern bleiben in einem geringen Abstande; die Leukocyten, die dem Kokkenhaufen am nächsten sind, sind zerfallen. LithioncarminGram $32 \%$.

Fig. 14. Infection mit Milzbrandbacillen; nach 8 Stunden. Die Leukocyten treten fast sämmtlich an den dem Bacillenhänfchen abgewendeten Seiten des Gefässes aus. Lithioncarmin-Gram 16\%.

Fig. 15. Infection mit vielen Milzbrandbacillen in eine tiefe Wunde; nach 12 Stunden; keine Zuwanderung von Leukocyten von unten, wohin die Resorption des Giftes stattfindet. (Hyperchemotaxis.) (Das Präparat hat sich beim Härten etwas gerollt, so dass die Infectionsstelle an der Spitze liegt.) Lithionearmin-Gram $7 \%$.

Fig. 16. Infection mit Staphylokokken in einen tiefen Schnitt; nach 8 Standen, zum Vergleich mit dem vorigen. Um die Infectionsstelle baben sich grosse Haufen von Leukocyten angesammelt; ebenso findet von unten massenhaftes Zuwandern von Leukocyten statt. Lithioncarmin-Gram 7\%/.

Fig. 17. Infection mit Milzbrandbacillen; nach 12 Stunden. Die Milzbrandbacillen ziehen sich in langen oder kürzeren Fäden zwischen den Leukocyten durch; nur wenige (rechts) sind phagocytirt. Lithioncarmin-Gram $320 / 1$.

Fig. 18. Infectionsstelle eines mit Milzbrand inficirten Hundes; nach 8 Stunden. Zum Vergleich mit dem vorigen. Fast sämmtliche Bacillen sind phagocytirt. Lithioncarmin-Gram ${ }^{32 \%}$. 
Zeitschrift für Hygiene. Bd. XLV.

'Tafel I.

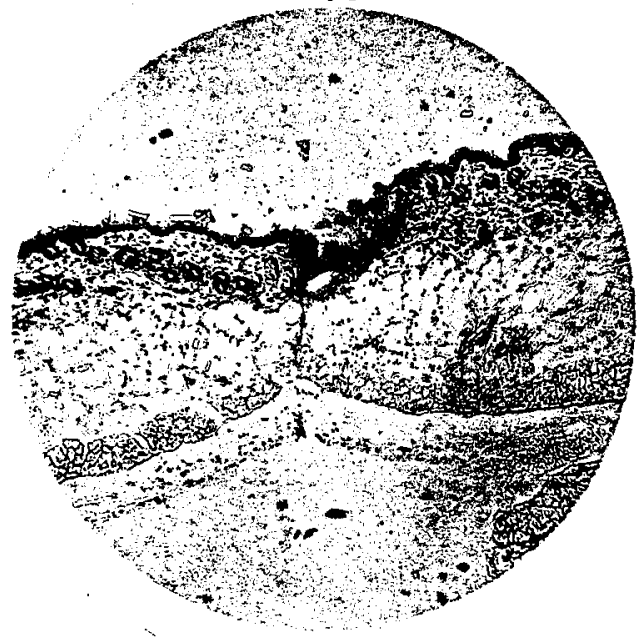

Fig. 1.

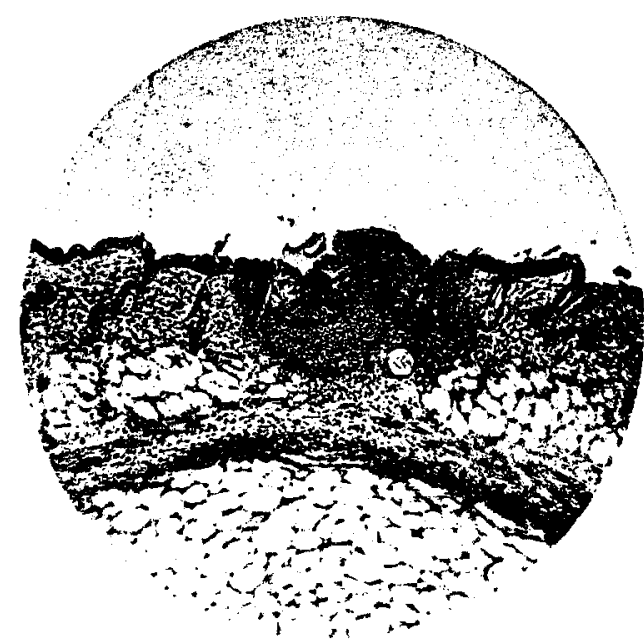

Fig. 2.

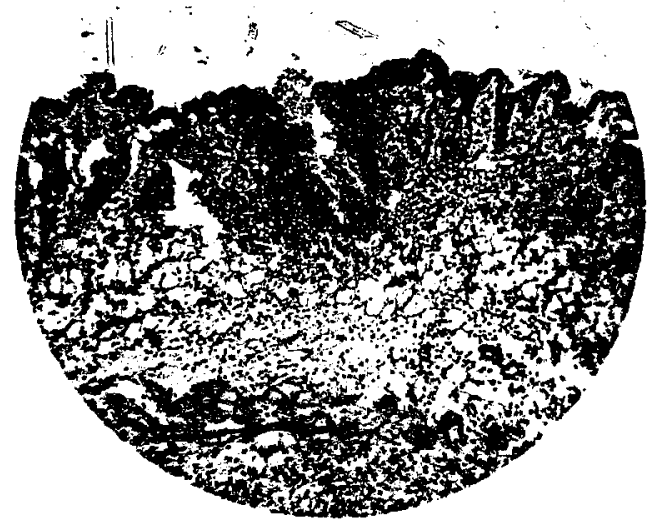

Fig. 3:
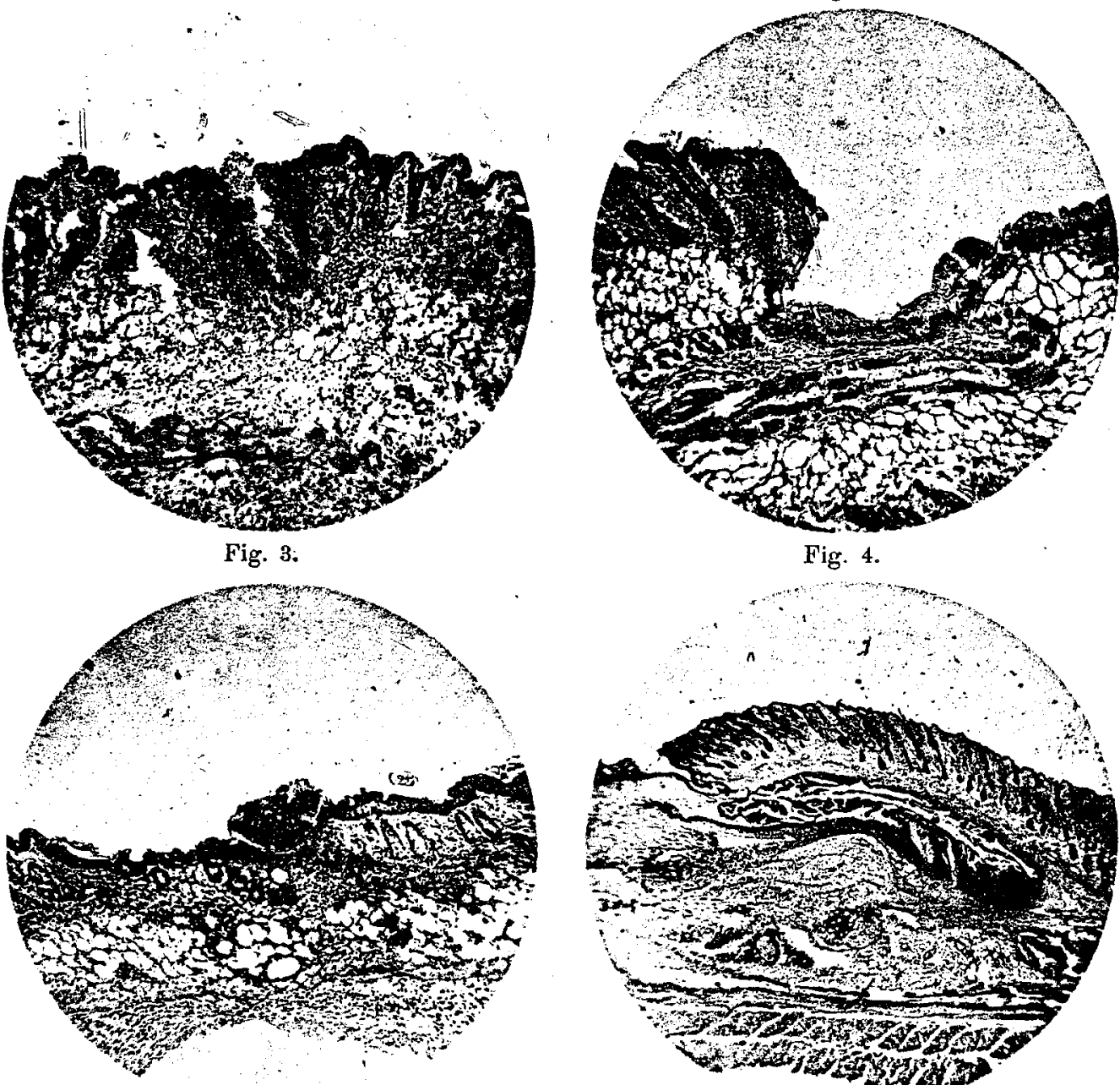

Fig. 4.

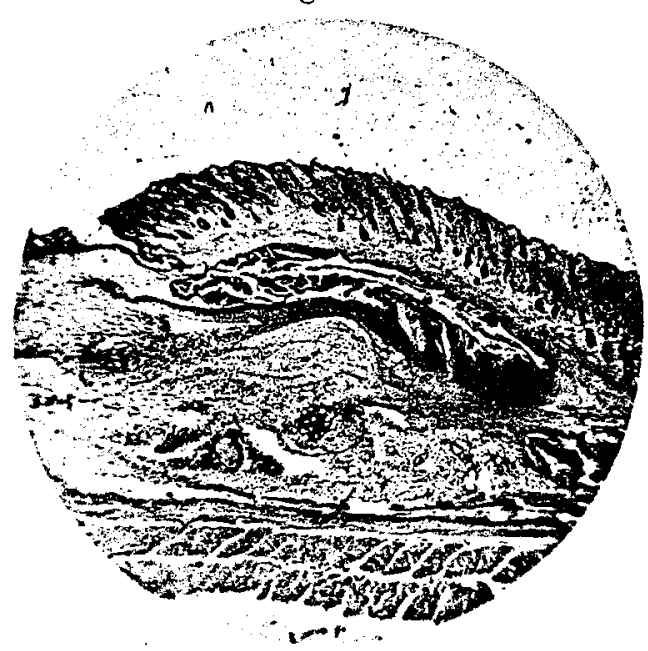

Fig. 5.

Fig. 6.

Verlag von VEIT \& COMP., Leipzig. 
Zeitschrift für Hygiene. Bd. XLV.

Tafel II.
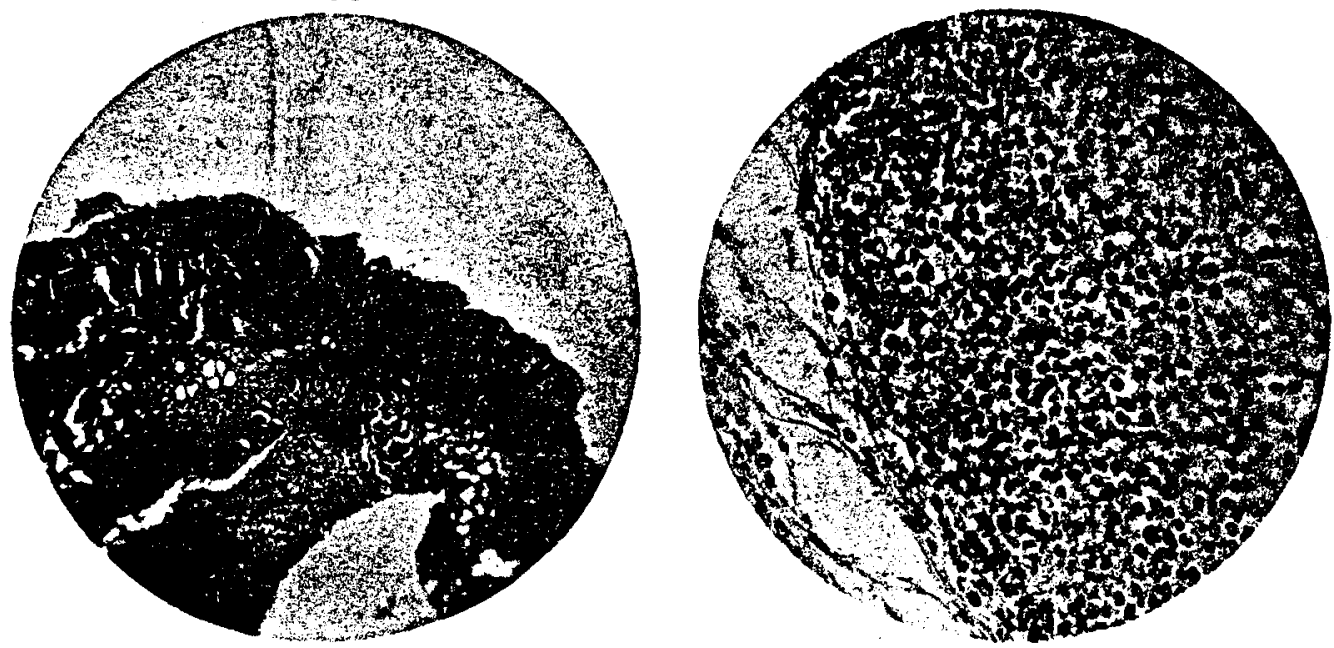

Fig. 7.

Fig. 8.

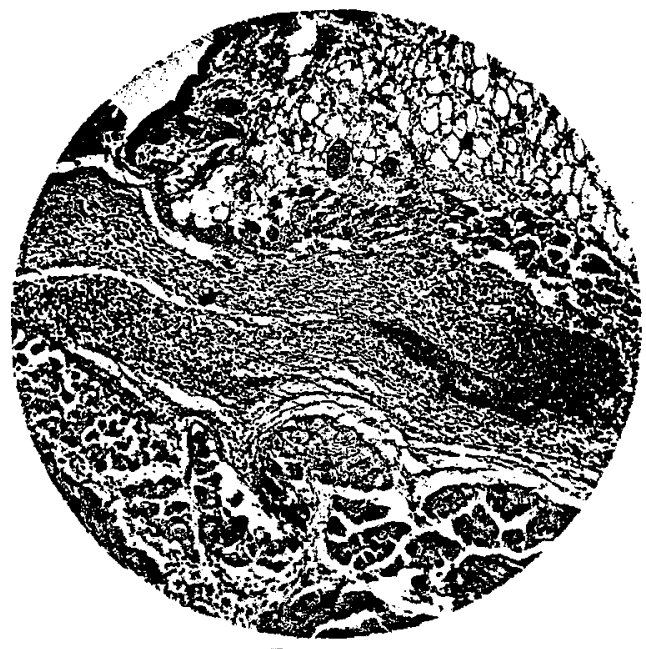

Fig. 9.

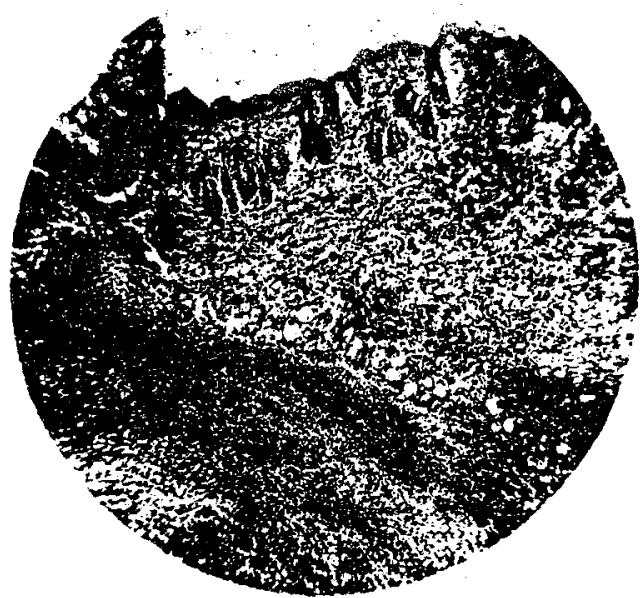

Fig. 11.

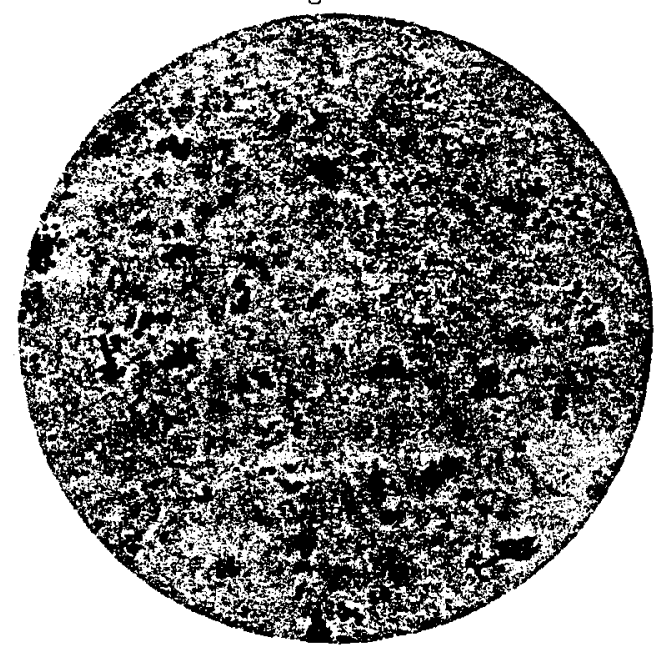

Fig. 10.

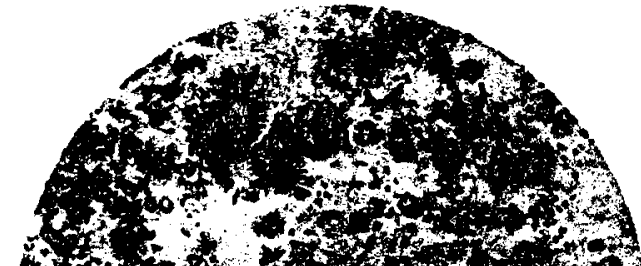

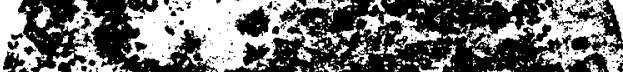

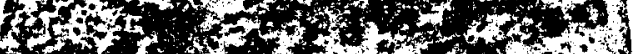

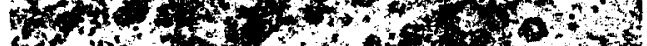

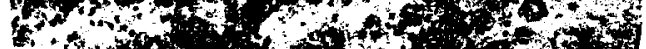

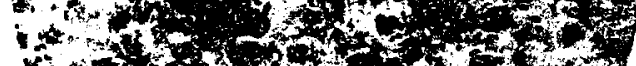

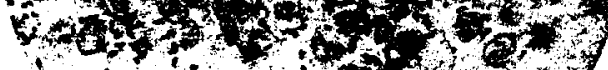
to top.

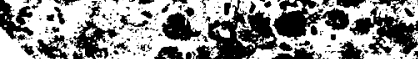
$+42, g$ $+3 x^{3}+1$

Fig. 12. 
Zeitschrilt' für Hygiene. Bd. XLSV.

Tafel III.

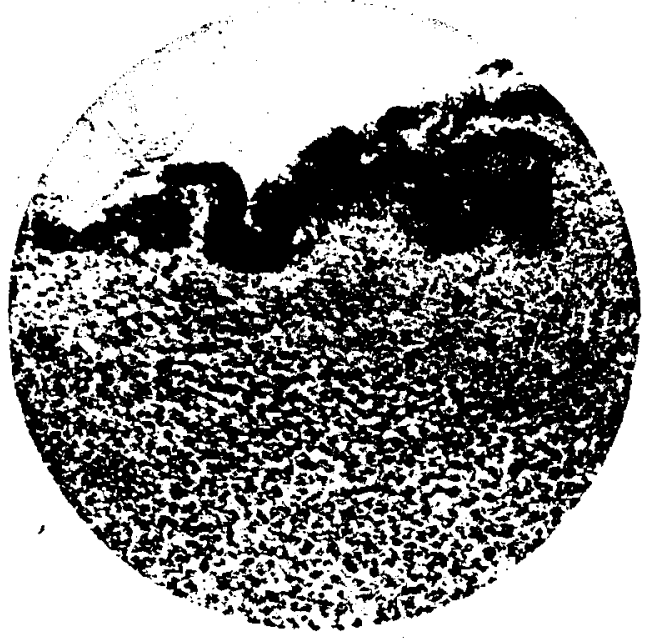

Fig. 13.
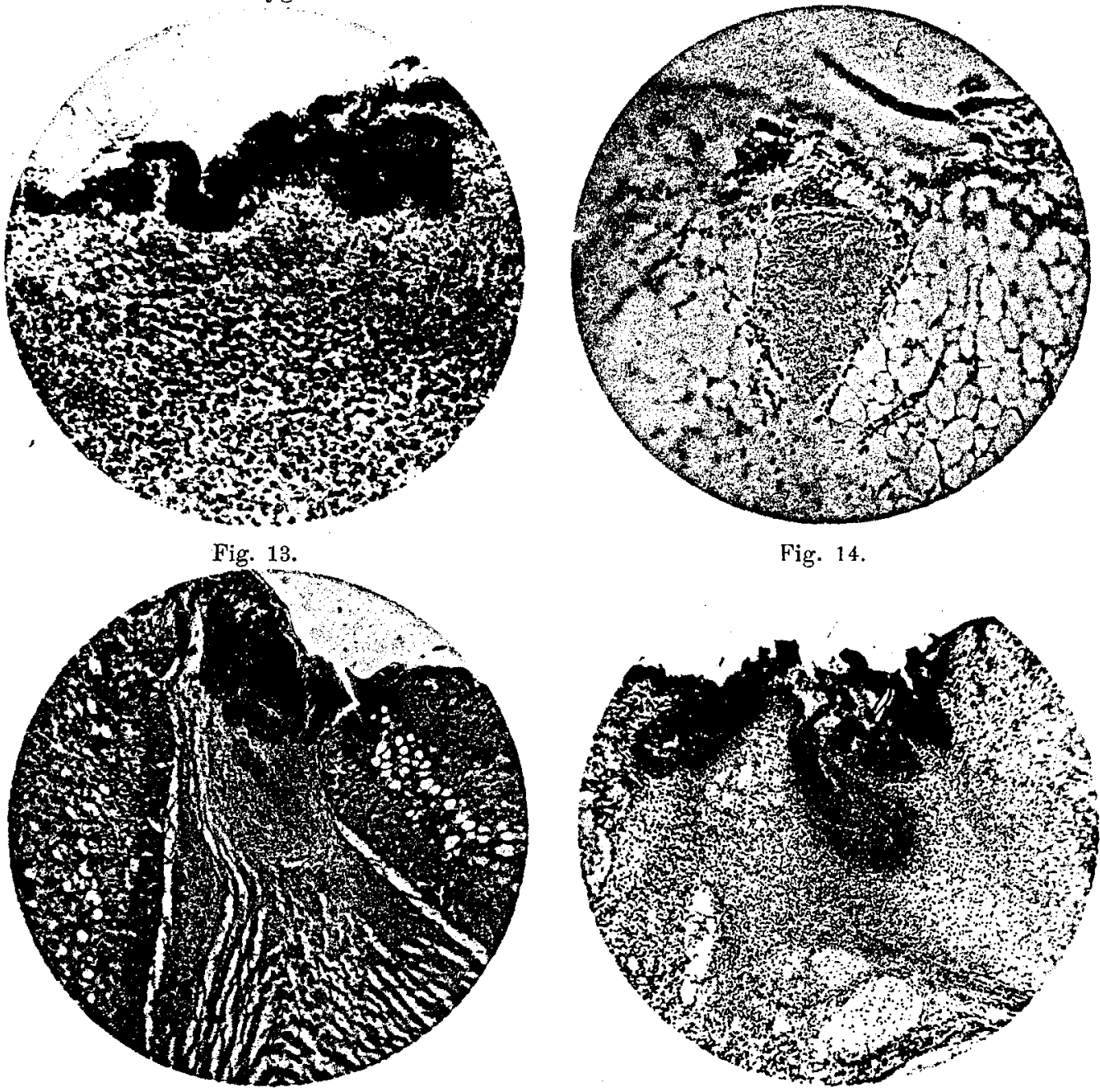

Fig. 14 .

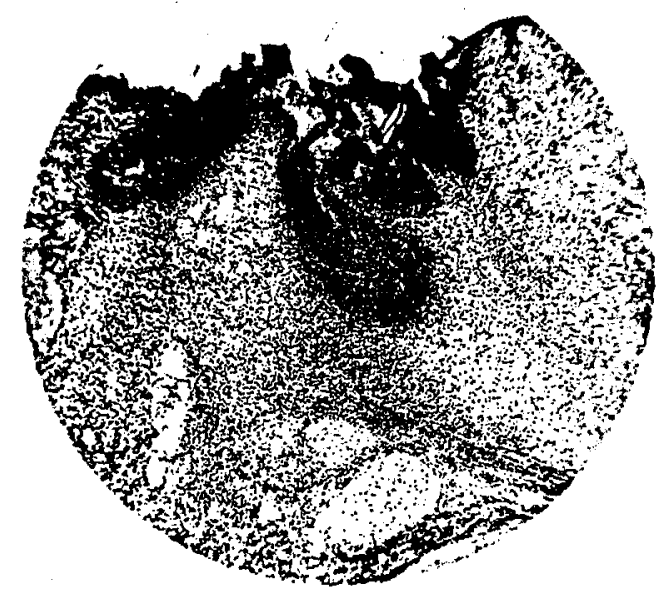

Fig. 15.

Fig. 16.

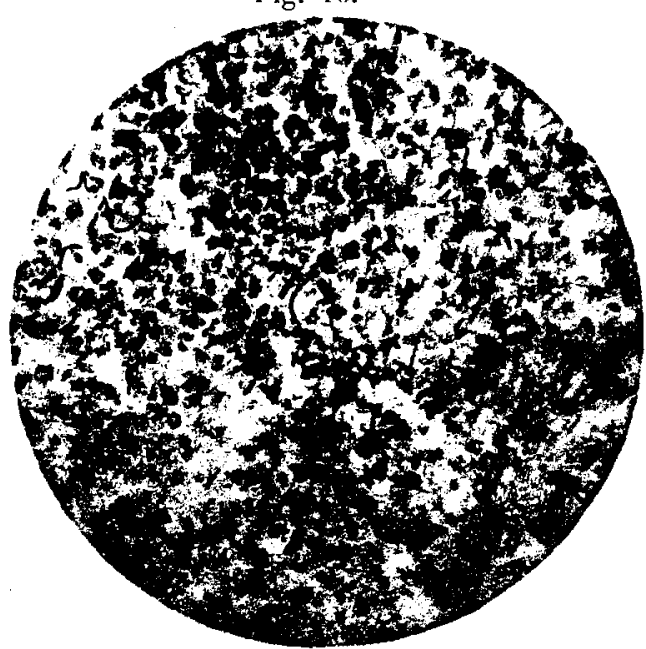

Fig. 17

Fig. 18. 